\title{
A Predictive Approach to Identify Geometrically Hazardous Road Segments and Evaluate the Relative Safety Effects of Design Alternatives
}

\author{
Alamirew Mulugeta Tola ${ }^{1,2, * \mathbb{D}}$, Tamene Adugna Demissie ${ }^{2}$, Fokke Saathoff ${ }^{1} \mathbb{D}$ and Alemayehu Gebissa ${ }^{1}$ \\ 1 Faculty of Agricultural and Environmental Sciences, Geotechnics and Coastal Engineering, \\ Rostock University, 18051 Rostock, Germany; fokke.saathoff@uni-rostock.de (F.S.); \\ alemayehu.gebissa@uni-rostock.de (A.G.) \\ 2 Faculty of Civil \& Environmental Engineering, Jimma University, Jimma 378, Ethiopia; \\ tamene.adugna@ju.edu.et \\ * Correspondence: lolaal728@gmail.com or alamirew.tola@uni-rostock.de
}

Citation: Tola, A.M.; Demissie, T.A.; Saathoff, F.; Gebissa, A. A Predictive Approach to Identify Geometrically Hazardous Road Segments and Evaluate the Relative Safety Effects of Design Alternatives. Sustainability 2022, 14, 3026. https://doi.org/ $10.3390 /$ su14053026

Academic Editor: Marco Guerrieri

Received: 3 February 2022

Accepted: 28 February 2022

Published: 4 March 2022

Publisher's Note: MDPI stays neutral with regard to jurisdictional claims in published maps and institutional affiliations.

Copyright: (c) 2022 by the authors. Licensee MDPI, Basel, Switzerland. This article is an open access article distributed under the terms and conditions of the Creative Commons Attribution (CC BY) license (https:/ / creativecommons.org/licenses/by/ $4.0 /)$.

\begin{abstract}
This study has two goals: First, to fill a gap in the use of the predictive approach for evaluating road safety performance in Ethiopia, the most recent analytical methods of the HSM predictive approach in IHSDM software were used to evaluate the safety and operational effects of the existing roadway geometric design. Second, to assure safety and a sustainable transportation system, the relative safety effects of design changes made to hazardous road segments were quantified. Based on the Crash Prediction Module (CPM) evaluation of IHSDM software, the study identified fifteen hazardous road segments on the existing rural two-lane roads of Addis Ababa to Chacha and Addis Ababa to Dillela. The design changes made to the hazardous road segments have resulted in a remarkable reduction in crash rate, especially on the first top five hazardous segments, where incredible improvements have been observed. The total safety benefits acquired by applying engineering mitigations to the fifteen identified hazardous segments are described as follows: $17.18 \%$ reduction in total crash frequency (crashes/year), 58.94\% reduction in crash rate (crashes/ $\mathrm{km} /$ year), and $58.86 \%$ reduction in travel crash rate (crashes/million veh- $\mathrm{km}$ ). In general, the study's findings underlined the effectiveness of performance-based road safety evaluation and design in providing safe, efficient, and economically-feasible roadway infrastructure. The IHSDM reports and graphical outputs assist decision-making in the roadway design process by providing a quantitative evaluation of the safety impact of various design features and identifying roadway segments with safety concerns. Additionally, IHSDM is a tool capable of saving time for Road Safety Audit (RSA) teams. The paper also outlined the need for a computerized crash database recording system in Ethiopia to develop jurisdiction-specific Safety Performance Functions (SPFs).
\end{abstract}

Keywords: hazardous road segments; HSM; IHSDM; relative safety performance; geometric design consistency; Safety Performance Functions (SPFs)

\section{Introduction}

Improving the safety of road infrastructure is one of the primary goals of transportation engineering. Highway safety can be significantly enhanced by using a scientific, methodical, consistent, and proactive approach to highway planning and design, as evidenced by decades of research and experience. Safety evaluations based on expected safety performance are a valuable technique to identify hazardous road locations in a highway network as well as site-specific safety concerns, especially given the cost of engineering studies and limited budgets [1]. The process of identifying hazardous road locations (also called blackspots, high-risk locations, hotspots, crash-prone zones, inconsistent, etc.) is defined as the process by which a road network is screened to detect places that require safety inquiries [2]. It has a long history in traffic engineering and is considered the primary 
and most frequent activity in the road network safety management process [3-5]. Road locations with a higher number of crashes than other similar locations due to local risk factors are considered hazardous or high-risk locations [6]. This means that high-risk locations are places where the geometric design and traffic circumstances have a major impact on the crash occurrence and can be mitigated using engineering remedies. The list of hazardous sites is prioritized for additional engineering research [3], and the most cost-effective projects are frequently selected to obtain the best outcomes with limited funds $[5,7]$.

In practice, network screening and road safety performance evaluation are the mandates of the transportation agency; however, developing a model is not a simple task [8], and it may be time-consuming regarding data requirements and staff qualification. Transportation agencies, including in Australia [9], Denmark [10], Finland, and Lithuania [11], have used a simple model that requires basic data only. In the Highway Safety Manual [4], simple models are also utilized as base models; the predictive approach followed in this manual are developing baseline models for the specified base conditions, and in order to account for changes in geometric design and operational characteristics (deviations from the specified base condition), crash modification factors (CMFs) are multiplied by baseline models. Based on data from two-lane rural highways in Italy, Cafiso et al. [12] developed crash modification functions (CMFs) of pavement surface and geometric design indicators for distinct crash types (total, run-off-the-road, and others), pavement conditions (dry and wet), and lighting conditions (daytime and nighttime). For developing CMFs, they used safety performance functions (SPFs) fitted with generalized linear modeling approaches and a negative binomial distribution error structure.

Crash prediction models (CPMs) are widely used to evaluate the safety of roadway design alternatives. In most cases, these models are developed and applied separately for road segments and intersections [4]. Many statistical models have been developed to address a variety of data-related issues (comprehensive reviews are provided in $[13,14]$ ). For instance, the Poisson and negative binomial regression models were used as base models in HSM's predictive approach [4]. The CPM, in general, predicts the expected frequency of crashes for roadway segments and intersections using geometric design and traffic operational variables. CPMs can be used to perform a variety of road safety management procedures, including road network screening, the development of crash modification factors $(C M F s)$, road safety performance evaluations, and economic analysis of design alternatives. CPMs evaluate and expose possible safety concerns, as well as assist in identifying potential safety improvements and quantifying their benefits [15]. In recent decades, CPMs based on road geometric design and traffic exposure have become an essential scientific and proactive tool in quantitative road safety management and have been the cornerstone of the AASHTO Highway Safety Manual (HSM) and the Australian National Risk Assessment Model (ANRAM) [4,16].

The Highway Safety Manual (HSM), published in 2010 by the American Association of State Highway and Transportation Officials (AASHTO), is a tool for support in achieving the goal of performance-based safety evaluation. HSM has become a well-known science-based decision-making tool that can be used to perform statistical evaluations on safety and other roadway transportation performance indicators (such as traffic operations, environmental impacts, and construction costs) [13]. By using the predictive approach of HSM, agencies or safety practitioners can be well guided in the process of identifying road sections with safety issues, developing mitigations to address them, evaluating the safety outcomes of those mitigations on resource allocation, and assessing the effectiveness of safety projects that have been built or implemented. Highway design and planning typically entail assessing a set of potential design alternatives to see how they affect a variety of aspects, such as safety, capacity, construction costs, societal expenses, environmental impacts, and so on. The HSM procedure can also be used to evaluate the safety implications of these design alternatives. Part C of the HSM's predictive approach [4] provides CPMs for various facility types (i.e., roadway segments and intersections) that comprise a set of safety performance 
functions (SPFs), crash modification factors (CMFs), and calibration factors $\left(\mathrm{C}_{\mathrm{x}}\right)$ to estimate the expected crash frequency at a certain location considering its geometric and traffic characteristics.

Due to its capacity to identify locations with safety issues, SPFs that precisely predict crash frequencies are worthwhile for transportation agencies. Thus, with the HSM, defining performance-based safety objectives and strategies has become more straightforward. The HSM has gained popularity, having been included in the Interactive Highway Safety Design Model (IHSDM) and subsequently implemented in the European crash prediction [17], Australian ANRAM [16], as well as in New Zealand [18]. The SPFs proposed in the HSM have been developed using roadway facilities that are representative of the United States as a whole; however, local and international users are encouraged to calibrate the SPFs for their jurisdictions. Calibration procedures are presented in Appendix A of HSM part C; they should be enhanced or adjusted considering the jurisdiction data availability, including geometric data, traffic, and crash history.

Statistical software or spreadsheets are commonly used to carry out the HSM analytical procedures, such as preparation of data, exploratory analysis, modeling, and computations. The FHWA (Federal Highway Administration) has designated the Highway Safety Design Practices and Criteria as the top research and development program [19]. The primary objective of this research program is to build a tool capable of evaluating the safety performance and cost-effectiveness of highway design alternatives in a CAD (Computer-Aided Design) interface. The project has been executed for a couple of years, and fully functional software known as the Interactive Highway Safety Design Model (IHSDM) has been developed. IHSDM evaluates the complete highway design, including both the highway alignments and cross-section as well as the roadside features. IHSDM is available now as a free software package and is used to estimate a project's substantive safety.

The IHSDM is comprised of five modules: Crash Prediction, Design Consistency, Policy Review, Traffic Analysis, and Driver/Vehicle. All are supplemented by nationallyrecognized research and design regulations [20]. The IHSDM Crash Prediction Module uses geometric design and traffic information to estimate the frequency and severity of crashes expected to occur on a given highway. Part C of the HSM is directly implemented by the IHSDM's Crash Prediction Module (CPM), which integrates the most up-to-date analytical approaches to carry out the following [21,22]:

- Predict crash frequency along with roadway segments, intersections, and interchanges;

- Identify sites in a road network or facility that have safety issues;

- Assess the relative safety effects of design alternatives or improvements;

- Evaluate the safety and cost-effectiveness of roadway design.

Several case studies conducted using IHSDM software revealed the need for substantial data collection, model adjustment, and calibration [23-26]. The default model must be updated and calibrated to realize the full potential of IHSDM for an accurate estimate of crash frequencies expected to occur on roadways with specific geometric design and traffic features. The calibration, if properly executed, can account for differences between the states used to develop the crash prediction model and local crash characteristics [1].

Current Ethiopian road design standards presume that the general safety performance on rural two-lane highways is provided by considering the policy minimum values which are specified based on the selected design speed [27]. The design speed is defined as "the maximum safe speed that can be maintained over a specified section of road when conditions are so favorable that the design features of the road govern the speed" [27]. In terms of safety, road design procedures based on the design speed concept have a number of flaws [28]. Considering design speed as the index that primarily defines the geometric standards of road elements as the only surrogate measure of safety demonstrates the gap of performance-based road design in Ethiopia. To bridge this gap, the current study evaluated the safety and operational effects of geometric designs on existing Ethiopian roads using the HSM predictive approach in IHSDM software. The use of the predictive HSM would bridge a gap in the road safety study, namely the lack of a standardized and approved manual as 
well as substantive highway safety evaluation [29]. As a decision-making tool, the HSM or IHSDM methodology should help transportation agencies make better use of limited funds by prioritizing safety planning and design alternatives based on the evaluation of road safety performance.

To benefit the full capacity of the CPM of IHSDM, it is recommended to develop or calibrate the base SPF and Crash Distribution Dataset on the Administration tool of the software. To do so, accurate and detailed crashes, roadway or intersection inventories, and traffic volume data are deemed necessary, and observed crashes must be assigned to their respective roadway segments or intersections [4]. In this study, the crash distribution dataset developed for the Oromia region by using local data was employed [30]. However, due to a lack of crash location data (i.e., crashes related to each roadway segment or intersection) in Ethiopia [31], the study was unable to calibrate the base SPF to the local jurisdiction. It is recommended to analyze the relative safety effects of different design alternatives in this case, such as when there is no local calibration data for SPF [32]. The predictive HSM has been effective for evaluating the relative safety effects of various design alternatives, or the uncalibrated models can be used to compare the relative safety effects to the no-build environment [32]. The objective of this research is to use the most up-to-date analytical methods of the IHSDM's Crash Prediction Module (CPM) to identify geometrically hazardous segments of rural two-lane roads and evaluate the relative safety performance of alternative designs or mitigations in a Computer-Aided Design (CAD) environment. Improving the safety of roads through improved design is a crucial task for a sustainable transportation system. Sustainability and safety are two ideas that are inextricably linked, since they both involve resource preservation. Whereas sustainability is commonly connected with environmental assets, safety is focused on human resources and the protection of human life. The fundamental concept is that a transportation system cannot be sustained unless it is safe for people, and nothing is more precious than human life. Road safety may be defined as not only the actions taken to lower the danger of road traffic injuries and fatalities, but also a belief in safety within the road system, as well as the guarantee that the road user will not be gravely injured or killed while using it. A safer transportation system is vital for sustainable development, since it may boost economic growth and expand accessibility owing to a safe and cost-effective transportation system, thus making the current study even more relevant.

\section{Materials and Methods}

Figure 1 depicts a flow diagram of the overall study process.

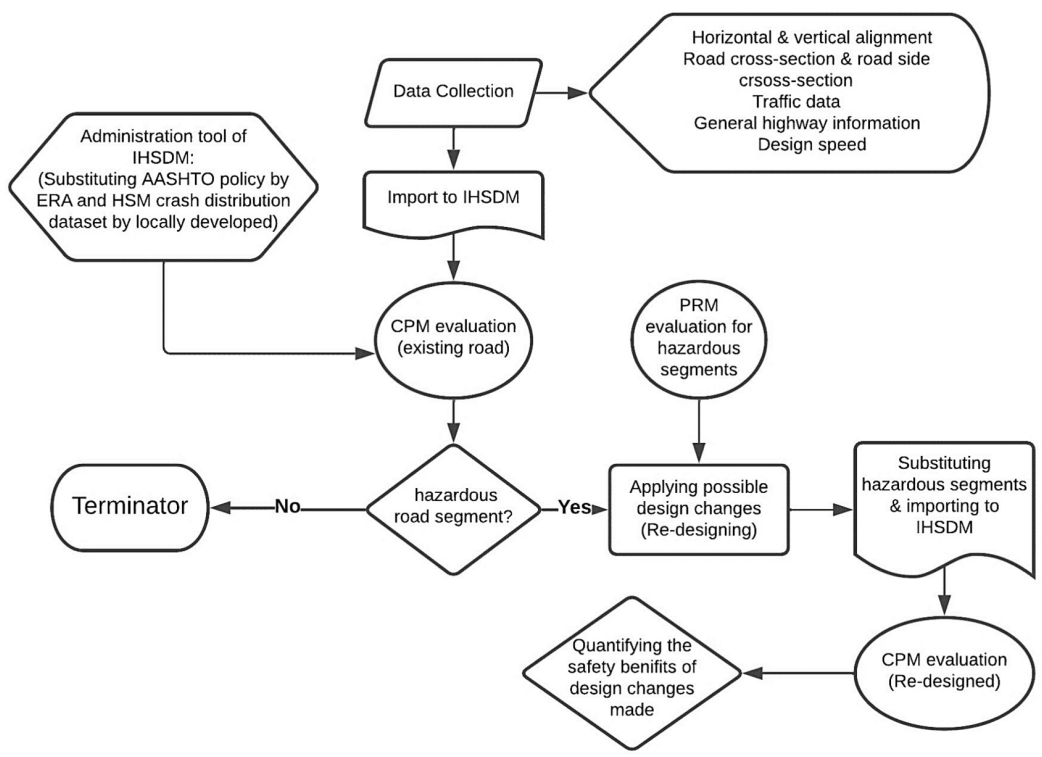

Figure 1. A flow diagram showing the overall study process. 


\subsection{Data Collection}

The current study was conducted on Ethiopian two-lane rural roads. Ethiopia is a landlocked country in eastern Africa, also known as the Horn of Africa. The country has a total land area of 1,126,829 $\mathrm{km}^{2}$ and borders Kenya, Somalia, Djibouti, South Sudan, Sudan, and Eritrea. With an estimated population of 114.9 million, it is Africa's second-most populous country following Nigeria [33]. Rural roads from Addis Ababa to Chacha (AA-Ch), Addis Ababa to Dillela (AA-D), and Addis Ababa to Modjo (AA-M) were considered for study based on the availability of as-built geometric design data. Table 1 presents the general roadway characteristics.

Table 1. General roadway information.

\begin{tabular}{ccccccc}
\hline Roads & $\begin{array}{c}\text { Functional } \\
\text { Class }\end{array}$ & Road No. & $\begin{array}{c}\text { Length } \\
\mathbf{( k m )}\end{array}$ & $\begin{array}{c}\text { Average Feature } \\
\text { Road AADT (vpd) }\end{array}$ & $\begin{array}{c}\text { Design } \\
\text { Class }\end{array}$ & $\begin{array}{c}\text { Surface } \\
\text { Type }\end{array}$ \\
\hline Addis Ababa-Chacha (AA-Ch) & Trunk Road & A2-1 & 95.05 & 3128 & DC7 & Paved \\
Addis Ababa-Dillela (AA-D) & Trunk Road & A5-1 & 83.96 & 7198 & DC7 & Paved \\
Addis Ababa-Modjo (AA-M) & Trunk Road & A1-1 & 57.80 & 19,540 & DC8 & Paved \\
\hline
\end{tabular}

Data were collected on all of the study roadways in compliance with the study's objective and the IHSDM data input requirements. When modeling highways, IHSDM offers various data fields that allow users to attain their preferred detailing. For each roadway, the Crash Prediction Module of IHSDM requires the following data inputs:

- Horizontal alignment;

- Vertical alignment;

- Road cross-section (i.e., lane, shoulder section, cross slope, and surface type);

- Traffic data (i.e., annual average daily traffic (AADT));

- General highway information (i.e., area type, functional class, and terrain);

- Roadside cross-section (i.e., driveway density and roadside hazard rating (RHR));

- Design speed.

The as-built geometric design data were obtained from the Ethiopian Roads Authority (ERA) and imported as a LandXML file into IHSDM software. From the imported as-built geometric design, all roadway data, such as horizontal alignment, vertical alignment, design speed, and road cross-section data, were documented on the software. For all the three roads studied, the Ethiopian Roads Authority also provided AADT data from 2010 to 2018. The SPF model developed by HSM for the undivided rural two-way two-lane road is only applicable to roads with a maximum AADT of $17,800 \mathrm{vpd}$. However, the obtained average AADT on Addis Ababa to Modjo road, (which is 19,540 vpd) exceeded the specified maximum AADT, so it was excluded from the analysis, and only the segregated rural roads of AA-Ch and AA-D were evaluated. Figure 2 depicts a map of the study area with the evaluated roads.

The functional classifications of the selected roads were obtained from Appendix A of the ERA Geometric Design Manual, 2013 [27]. Accordingly, both roads are documented as Trunk Road with the road numbers of A2-1 and A5-1 for the Addis Ababa to Chacha (AA-Cha) and Addis Ababa to Dillela (AA-D) roads, respectively (illustrated in Table 1). The rural roads were segregated from urban roads based on their roadway characteristics (i.e., cross-section types), surrounding population, and land uses. Then, the segregated rural roads were used for analysis as the area type. For driveway density, terrain, and roadside hazard rating, Google Earth and Street Map were used. Finally, all the necessary information of the collected data were imported and documented into IHSDM software for CPM evaluation. 


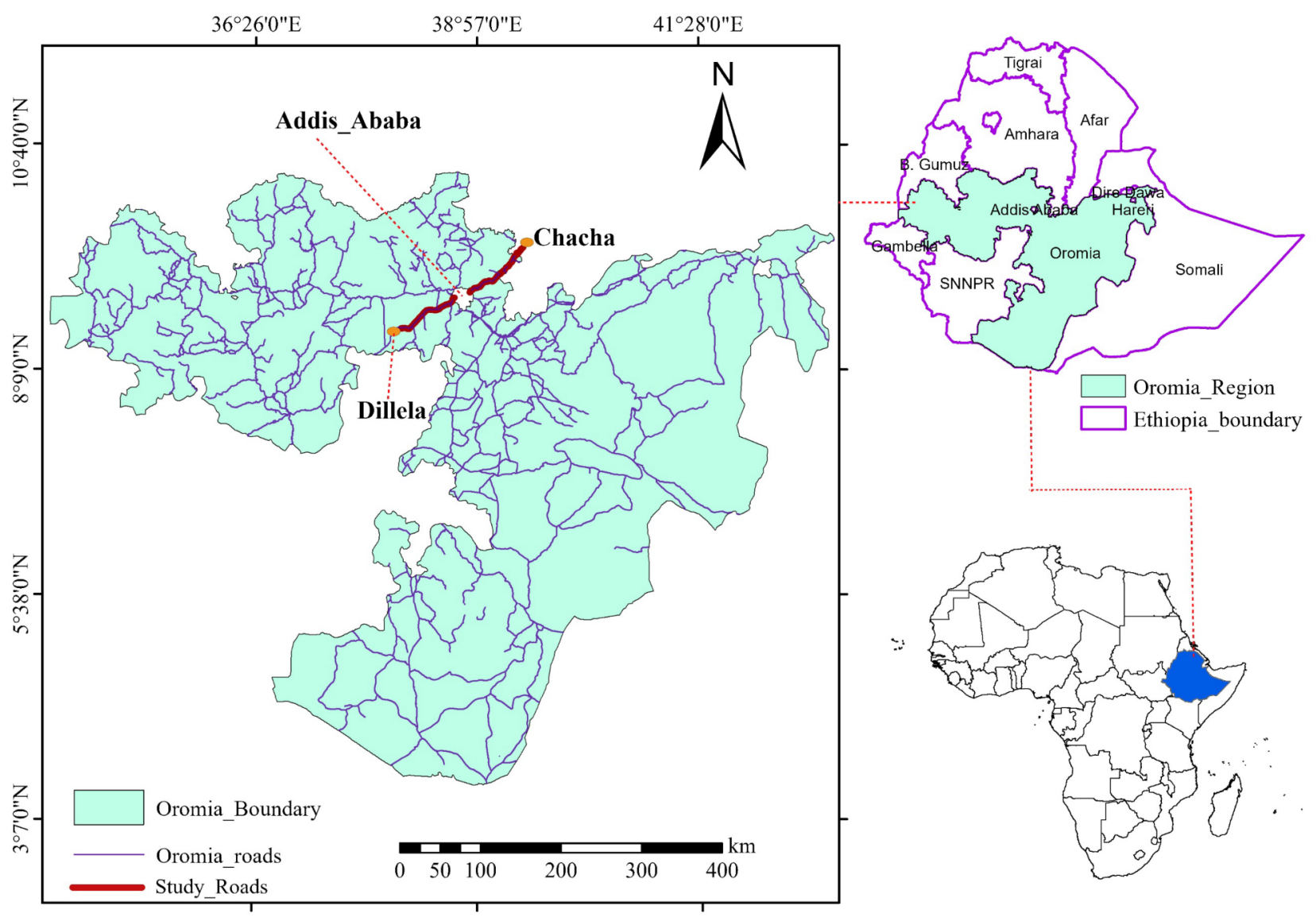

Figure 2. Map of the study area.

\section{2. $C P M$ Evaluation}

After importing and documenting all the necessary information of the analysis roads into IHSDM software, the CPM evaluation was executed, and the predicted average crash frequency and crash rate resulted had been used to identify the hazardous road segments. The CPM incorporated in IHSDM is the predictive approach of the Highway Safety Manual (HSM). In this study, the predictive model in Part C of the HSM for the undivided rural two-lane two-way roadway facility type has been used. Although the predictive models differ depending on the facility and site type, they all share the same basic components, as illustrated in Equation (1) [4].

$$
N_{\text {predicted }}=N_{S P F x} \times\left(C M F_{1 x} \times C M F_{2 x} \times \ldots \times C M F_{y x}\right) \times C_{x}
$$

where $N_{\text {predicted }}$ is predicted average crash frequency for a specific year for site type $x$ (crashes/year); $N_{S P F x}$ is predicted average crash frequency determined for 'base conditions' of the SPF developed for site type $x ; C M F_{1 x}, C M F_{2 x}, \ldots, C M F_{y x}$ are crash modification factors specific to site type $x$ and specific geometric design and traffic control features $y$; and $C_{x}$ is a calibration factor to adjust SPF for local conditions for site type $x$.

Safety performance functions (SPFs) utilize known information about a roadway, such as geometry and annual average daily traffic (AADT), to estimate the average crash frequency for a facility type with specified 'base conditions'. SPFs are mathematical regression models developed for roadway segments and intersections by assuming that crash frequencies follow a negative binomial distribution. The SPF for rural two-lane two-way roadway segments, such as the facility types preferred in the current study, that meet the HSM's 'base conditions' is shown in Equation (2) [4]. The following are the HSM 'base conditions' for rural two-lane two-way roadway segments: lane width, $12 \mathrm{ft}$; shoulder 
width, $6 \mathrm{ft}$; shoulder type, paved; roadside hazard rating, 3; driveway density, 5 driveways per mile; horizontal curvature, none; vertical curvature, none; centerline rumble strips, none; passing lanes, none; two-way left-turn lanes, none; lighting, none; automated speed enforcement, none; and grade level of $0 \%$ [4]. Whenever a base condition is not met, a crash modification factor $(C M F)$ is applied to the model.

$$
N_{S P F x}=A A D T \times L \times 365 \times 10^{-6} \times e^{-0.312}
$$

where $A A D T$ is the annual average daily traffic volume on a roadway segment (vpd) and $A A D T_{\max }=17,800 \mathrm{vpd} ; L$ is the length of roadway segment (miles).

CMFs are multiplied by a base model of Equation (2) to account for the differences between 'base conditions' (condition ' $a$ ') and the site conditions under consideration (condition ' $b$ '). CMFs are used to address the effects of individual geometric design and traffic control features on the SPF estimate of predicted crash frequency, and their computation is shown in Equation (3). The IHSDM software incorporates all of the twelve CMFs available in HSM for rural two-lane two-way roadway segments, and the current study implemented them to address the effects of site-specific geometric design and traffic control characteristics. A CMF has a value of 1.00 under 'base conditions', while values less than 1.00 imply that alternative treatment reduces the predicted crash frequency, and values greater than 1.00 indicate that alternative treatment increases the predicted crash frequency compared to the 'base condition'. HSM includes twelve CMFs for rural two-lane two-way roadway segments (see Table 2). These CMFs are taken into account in this study, and readers are encouraged to refer to the HSM manual for detailed equations for each CMF [4].

$$
C M F=\frac{\text { Predicted average crash frequency with condition ' } b \text { ' }}{\text { Predicted average crash frequency with condition ' } a \text { ' }}
$$

Table 2. HSM crash modification factors for rural two-lane two-way roadway segments.

\begin{tabular}{ccc}
\hline Facility Type & $C M F$ & CMF Description \\
\hline & $C M F_{1 \mathrm{r}}$ & Lane Width \\
& $C M F_{2 \mathrm{r}}$ & Shoulder Width and Type \\
& $C M F_{3 \mathrm{r}}$ & Horizontal Curves: Length, Radius, and \\
& $C M F_{4 \mathrm{r}}$ & Presence or Absence of Spiral Transitions \\
Rural Two-Lane & $C M F_{5 \mathrm{r}}$ & Horizontal Curves: Superelevation \\
Two-Way & $C M F_{6 \mathrm{r}}$ & Grades \\
Roadway Segments & $C M F_{7 \mathrm{r}}$ & Driveway Density \\
& $C M F_{8 \mathrm{r}}$ & Centerline Rumble Strips \\
& $C M F_{9 \mathrm{r}}$ & Passing Lanes \\
& $C M F_{10 \mathrm{r}}$ & Two-Way Left-Turn Lanes \\
& $C M F_{11 \mathrm{r}}$ & Roadside Design \\
& $C M F_{12 \mathrm{r}}$ & Lighting \\
& & Automated Speed Enforcement \\
\hline
\end{tabular}

A calibration factor $\left(C_{x}\right)$ is also multiplied by the crash frequency predicted by the statistical base model to account for the differences between the general local conditions (site-specific condition) and HSM conditions (states used to develop HSM). Whenever the observed number of crashes for the evaluation period is available, Equation (4) can be used to compute the calibration factor $\left(C_{x}\right)$. The study was unable to calibrate the base SPF to local jurisdiction due to a lack of crash location data (i.e., crashes related to each roadway segment or intersection) in the study area [31]. In this case, such as when there is no local calibration data for SPF, it is recommended to evaluate the relative safety impacts of different design alternatives [32]. As a result, the current study was devoted to analyzing the safety implications of different design alternatives.

$$
C_{x}=\frac{\sum_{\text {All }} \text { Observed crashes }}{\sum_{\text {All }} \text { Predicted crashes }}
$$


However, because different highway geometric characteristics could have a varying effect on collision type and severity, it is preferable to predict crashes in terms of severity and collision type proportions [34,35]. Whereas SPFs predict crash frequency as an aggregate, HSM provides a default crash distribution dataset for rural two-lane two-way roadway segments based on HSIS (Highway Safety Information System) data to distinguish the predicted crash frequency into collision type and crash severity. Since these distributions differ from jurisdiction to jurisdiction [30,36], HSM recommends that as part of the calibration procedure, this default crash distribution dataset be replaced with local crash distribution estimates. In this study, the crash distribution dataset of the Oromia region, which was developed and validated using the IHSDM Administration Tool [30], was used. Furthermore, in this study, the ERA Geometric Design Manual (2013) replaced the AASHTO superelevation policy as a calibration procedure to the local design standard in the IHSDM Administration Tool.

\subsection{Identifying Geometrically Hazardous Road Segments and the Possible Design Alternatives}

The CPM evaluation of IHSDM necessitates the selection of a calibrated/uncalibrated $\mathrm{SPF}$, a $C M F$, a superelevation policy, a crash distribution dataset, and an evaluation period. In this study, an evaluation period of twenty consecutive years, from 2010 to 2029, was preferred for analysis. Finally, the CPM evaluation was executed for both of the studied rural two-lane two-way roadway segments, with the uncalibrated SPF, HSM's CMFs, ERA superelevation policy, Oromia's crash distribution dataset, and for 20 years of the evaluation period (i.e., 2010 as the first year of analysis and 2029 as the final year of analysis). The inconsistencies in roadway segments were identified based on the predicted crash frequency and crash rate report of the IHSDM CPM evaluations. To identify and prioritize the hazardous segments, the predicted travel crash rate (crashes/million veh-km) result of each homogeneous roadway segment was used.

Though applying engineering mitigations to hazardous road segments can improve safety, these mitigation procedures are only small patches to the entire roadway facility [1]. With safety in mind, the identified hazardous road segments were redesigned using AutoCAD Civil 3D-2019 software. Before redesigning, the IHSDM's Policy Review Module (PRM) was evaluated using the ERA Geometric Design Manual (2013) and AADT. The PRM evaluation report is useful for identifying issues with specific road geometric elements. The radius of a curve is primarily checked for its adequacy, since the radius or degree of curvature has a significant impact on the occurrence of a crash [37]. When the existing curvature does not meet the policy minimum, the curve radius is increased to meet the minimum requirement or to the maximum extent possible. The curve length is then checked against the policy minimum. If the result is inadequate, the curve radius is expanded as much as possible to meet the standard value.

To ensure safety, appropriate superelevation, as well as curve widening, were provided based on the policy minimum. Where there was difficulty to modify or make good alternative designs, very sharp curves were eliminated. Furthermore, based on the road functional classification and AADT, the minimum policy for lane width and shoulder width was checked and attempted to meet the standard as much as possible while considering the available right-of-way through site inspection and Google Earth and Street Map. The procedure was repeated for all identified geometrically hazardous road segments. After implementing all engineering mitigations in AutoCAD Civil 3D software, the finally modified highway data were imported into IHSDM software for further CPM evaluation, such as substituting the hazardous segments. To assess the relative safety effects of design alternatives, the current CPM evaluation was also carried out using similar analysis parameters as the previous one, such as the uncalibrated SPF, HSM's CMFs, ERA superelevation policy, Oromia's crash distribution dataset, and for 20 years of the evaluation period (i.e., 2010 as the first year of analysis and 2029 as the final year of analysis). Finally, the benefits of engineering mitigations made to the identified inconsistencies in the roadway segments were compared and quantified. 


\section{Results and Discussions}

The safety of the road network can be improved by redesigning and fixing the hazardous segments in the roadway network; however, these mitigative tasks are only simple spots to the roadway network [1]. In recent times, it has become practical and accepted that a valuable number of crashes could have been prevented if the planning and design of highways had been done in a scientific, consistent, and proactive manner. The current study aimed to identify hazardous road segments (locations with higher predicted crashes) and apply engineering mitigations by redesigning them; the findings are outlined in this section.

As a case study, we examined three rural two-lane roads in Ethiopia: (a) Addis Ababa to Chacha (AA-Ch), (b) Addis Ababa to Dillela (AA-D) on the way to Welkite town, and (c) Addis Ababa to Modjo (AA-M) roads. The SPF model developed by HSM for the undivided rural two-way two-lane road is only applicable to roads with a maximum AADT of 17,800 vpd. However, the obtained average AADT on Addis Ababa to Modjo road, AA-M (which is $19,540 \mathrm{vpd}$ ), exceeded the specified maximum AADT, so it was excluded from the analysis, and only the segregated rural roads of $\mathrm{AA}-\mathrm{Ch}$ and $\mathrm{AA}-\mathrm{D}$ were evaluated.

\subsection{Identifying Hazardous Road Segments}

The IHSDM CPM was carried out for all rural roads selected for evaluation, and the inconsistencies in road sections were identified and prioritized based on their safety performance evaluation. For each homogeneous segment, the CPM evaluation of IHSDM reports the predicted total crash frequency (crashes/year), predicted crash rate (crashes/km/year) and predicted travel crash rate (crashes/million veh- $\mathrm{km}$ ). For assessing the relative safety performance of highways, it is better to consider the length and AADT of roadway segments, i.e., the predicted travel crash rate (crashes/million veh-km). In this study, hazardous road segments were identified and prioritized based on the CPM reports of the predicted travel crash rate (crashes/million veh-km). Roadway segments that have a predicted travel crash rate of more than 1.4 (crashes/million veh- $\mathrm{km}$ ) are documented as hazardous. Accordingly, fifteen roadway segments on both AA-Ch and AA-D roads were detected as hazardous by horizontal design element diagnosis, and the results are exhibited in Table 3.

Table 3. Hazardous road segments based on the predicted travel crash rate (crashes/million veh-km) by horizontal design element.

\begin{tabular}{|c|c|c|c|c|c|c|}
\hline Rank & Highway & Title & $\begin{array}{l}\text { Start Location } \\
\text { (Station, m) }\end{array}$ & $\begin{array}{l}\text { End Location } \\
\text { (Station, } \mathrm{m} \text { ) }\end{array}$ & $\begin{array}{l}\text { Predicted Travel Crash Rate } \\
\text { (Crashes/Million veh-km) }\end{array}$ & Length (m) \\
\hline \multirow{3}{*}{1} & \multirow{3}{*}{ AA-D } & Spiral Curve & $4+853.484$ & $4+855.420$ & 4.84 & \multirow{3}{*}{9.09} \\
\hline & & Simple Curve & $4+855.420$ & $4+860.634$ & 4.84 & \\
\hline & & Spiral Curve & $4+860.634$ & $4+862.570$ & 4.84 & \\
\hline \multirow[t]{2}{*}{2} & \multirow[t]{2}{*}{$\mathrm{AA}-\mathrm{Ch}$} & Simple Curve & $9+933.489$ & $9+971.900$ & 2.79 & \multirow[t]{2}{*}{38.41} \\
\hline & & Spiral Curve & $7+017.218$ & $7+024.745$ & 2.5 & \\
\hline \multirow[t]{3}{*}{3} & \multirow{3}{*}{ AA-D } & Simple Curve & $7+024.745$ & $7+096.671$ & 2.5 & \multirow{3}{*}{86.98} \\
\hline & & Spiral Curve & $7+096.671$ & $7+104.199$ & 2.5 & \\
\hline & & Spiral Curve & $11+972.179$ & $11+979.389$ & 2.29 & \\
\hline \multirow[t]{3}{*}{4} & \multirow{3}{*}{ AA-D } & Simple Curve & $11+979.389$ & $12+076.889$ & 2.33 & \multirow{3}{*}{111.92} \\
\hline & & Spiral Curve & $12+076.889$ & $12+084.098$ & 2.38 & \\
\hline & & Spiral Curve & $14+725.232$ & $14+738.581$ & 2.1 & \\
\hline \multirow{2}{*}{5} & \multirow[t]{2}{*}{ AA-D } & Simple Curve & $14+738.581$ & $14+798.507$ & 2.1 & \multirow{2}{*}{86.62} \\
\hline & & Spiral Curve & $14+798.507$ & $14+811.856$ & 2.1 & \\
\hline \multirow[b]{2}{*}{6} & \multirow[b]{2}{*}{ AA-D } & Simple Curve & $9+650.000$ & $9+650.380$ & 2.01 & \multirow[b]{2}{*}{14.21} \\
\hline & & Spiral Curve & $9+650.380$ & $9+664.208$ & 2.01 & \\
\hline 7 & $\mathrm{AA}-\mathrm{Ch}$ & Simple Curve & $29+008.489$ & $29+043.274$ & 2 & 34.78 \\
\hline
\end{tabular}


Table 3. Cont.

\begin{tabular}{|c|c|c|c|c|c|c|}
\hline Rank & Highway & Title & $\begin{array}{l}\text { Start Location } \\
\text { (Station, m) }\end{array}$ & $\begin{array}{l}\text { End Location } \\
\text { (Station, } \mathrm{m})\end{array}$ & $\begin{array}{l}\text { Predicted Travel Crash Rate } \\
\text { (Crashes/Million veh-km) }\end{array}$ & Length (m) \\
\hline & \multirow{3}{*}{ AA-D } & Spiral Curve & $11+346.228$ & $11+356.950$ & 1.91 & \\
\hline \multirow[t]{2}{*}{8} & & Simple Curve & $11+356.950$ & $11+434.762$ & 1.91 & 99.26 \\
\hline & & Spiral Curve & $11+434.762$ & $11+445.484$ & 1.91 & \\
\hline \multirow[t]{2}{*}{9} & \multirow[t]{2}{*}{$\mathrm{AA}-\mathrm{Ch}$} & Simple Curve & $42+500.015$ & $42+613.424$ & 1.81 & 113.27 \\
\hline & & Spiral Curve & $12+124.150$ & $12+137.565$ & 1.73 & \\
\hline \multirow[t]{3}{*}{10} & \multirow[t]{3}{*}{ AA-D } & Simple Curve & $12+137.565$ & 12 + 197.977 & 1.73 & 87.24 \\
\hline & & Spiral Curve & $12+197.977$ & $12+211.392$ & 1.73 & \\
\hline & & Spiral Curve & $10+108.127$ & $10+119.643$ & 1.62 & \\
\hline \multirow[t]{2}{*}{11} & \multirow[t]{2}{*}{ AA-D } & Simple Curve & $10+119.643$ & $10+229.309$ & 1.64 & 132.70 \\
\hline & & Spiral Curve & $10+229.309$ & $10+240.825$ & 1.64 & \\
\hline \multirow[t]{2}{*}{12} & \multirow[t]{2}{*}{$\mathrm{AA}-\mathrm{Ch}$} & Simple Curve & $39+549.882$ & $39+608.489$ & 1.59 & 58.61 \\
\hline & & Spiral Curve & $15+643.704$ & $15+658.617$ & 1.55 & \\
\hline \multirow[t]{2}{*}{13} & \multirow[t]{2}{*}{ AA-D } & Simple Curve & $15+658.617$ & $15+723.639$ & 1.55 & 94.85 \\
\hline & & Spiral Curve & $15+723.639$ & $15+738.552$ & 1.64 & \\
\hline \multirow[t]{2}{*}{14} & \multirow[t]{2}{*}{$\mathrm{AA}-\mathrm{Ch}$} & Simple Curve & $10+016.518$ & $10+204.330$ & 1.54 & 187.81 \\
\hline & & Spiral Curve & $6+831.965$ & $6+850.095$ & 1.54 & \\
\hline \multirow[t]{2}{*}{15} & \multirow{2}{*}{ AA-D } & Simple Curve & $6+850.095$ & $6+904.803$ & 1.42 & 90.97 \\
\hline & & Spiral Curve & $6+904.803$ & $6+922.933$ & 1.4 & \\
\hline
\end{tabular}

A total of $1.25 \mathrm{~km}$ roadway segments was identified as hazardous, accounting for $0.89 \%$ of the total 140.66-kilometer rural roads evaluated. The total predicted crash frequency for the entire road network evaluated was 140.41 crashes/year, whereas the hazardous segment had a crash frequency of 5.00 crashes/year, accounting for $3.56 \%$ of the total crash frequency despite being only $0.89 \%$ of the total length. Overall, the average predicted crash rate for rural roads evaluated was 0.998 (crashes $/ \mathrm{km} /$ year), whereas the predicted crash rate for hazardous road segments was more than four times as hazardous, at 4.011 (crashes $/ \mathrm{km} /$ year), and the details are illustrated in Table 4. As a result of the higher crash rates perceived on the identified hazardous road segments, implementing engineering mitigations on these segments has the potential to economically improve overall highway safety.

Table 4. Hazardous road segments versus overall rural roads evaluated.

\begin{tabular}{|c|c|c|c|c|c|c|c|}
\hline Title & $\mathrm{AADT}_{\text {avg }}$ & $\begin{array}{c}\text { Length } \\
(\mathrm{km})\end{array}$ & $\begin{array}{l}\text { Length } \\
\text { Proportion } \\
\text { (\%) }\end{array}$ & $\begin{array}{l}\text { Total Predicted } \\
\text { Crashes for } \\
\text { Evaluation } \\
\text { Period }\end{array}$ & $\begin{array}{c}\text { Predicted } \\
\text { Total Crash } \\
\text { Frequency } \\
\text { (Crashes/year) }\end{array}$ & $\begin{array}{c}\text { Average } \\
\text { Predicted Crash } \\
\text { Rate (Crashes/k } \\
\text { m/year) }\end{array}$ & $\begin{array}{c}\text { Average Predicted } \\
\text { Travel Crash Rate } \\
\text { (Crashes/Million } \\
\text { veh-km) }\end{array}$ \\
\hline & \multicolumn{7}{|c|}{ All Rural Roads Evaluated } \\
\hline AA-Ch Road & 3128 & 71.030 & 50.50 & 865.844 & 43.293 & 0.609 & 0.534 \\
\hline AA-D Road & 7198 & 69.628 & 49.50 & 1942.450 & 97.122 & 1.395 & 0.531 \\
\hline \multirow[t]{3}{*}{ Total } & & 140.658 & & 2808.29 & 140.41 & \multicolumn{2}{|c|}{ Mean average per length proportion } \\
\hline & & & & & & $0.998^{1}$ & $0.532^{2}$ \\
\hline & \multicolumn{7}{|c|}{ Hazardous Road Segments } \\
\hline AA-Ch Road & 3128 & 0.433 & 34.75 & 17.469 & 0.874 & 2.017 & 1.767 \\
\hline AA-D Road & 7198 & 0.813 & 65.25 & 82.511 & 4.126 & 5.073 & 1.931 \\
\hline Total & & 1.246 & & 99.980 & 5.00 & \multicolumn{2}{|c|}{ Mean average per length proportion } \\
\hline & & & & & & $4.011^{3}$ & $1.874^{4}$ \\
\hline Total coverage & & $0.89 \%$ & & $3.56 \%$ & $3.56 \%$ & \multicolumn{2}{|c|}{ Hazardousness compared to overall } \\
\hline & & & & & & $401.80 \%$ & $351.96 \%$ \\
\hline
\end{tabular}

${ }^{1} \mathrm{AA}-\mathrm{Ch}_{(\text {Crashes } / \mathrm{km} / \mathrm{yr})} \times \mathrm{AA}-\mathrm{Ch}_{(\text {Length Proportion })}+\mathrm{AA}-\mathrm{D}_{(\text {Crashes } / \mathrm{km} / \mathrm{yr})} \times \mathrm{AA}-\mathrm{D}_{(\text {Length Proportion })}=0.609 \times 50.5 \%+$ $1.395 \times 49.5 \%=0.998 .{ }^{2} \mathrm{AA}-\mathrm{Ch}_{(\text {Crashes } / \text { million veh-km) }} \times \mathrm{AA}-\mathrm{Ch}_{(\text {Length Proportion) }}+\mathrm{AA}-\mathrm{D}_{(\text {Crashes }} /$ million veh-km) $\times$ AA$\mathrm{D}_{\text {(Length Proportion) }}=0.534 \times 50.5 \%+0.531 \times 49.5 \%=0.532 .{ }^{3} \mathrm{AA}-\mathrm{Ch}_{(\text {Crashes } / \mathrm{km} / \mathrm{yr})} \times \mathrm{AA}-\mathrm{Ch}_{(\text {Length Proportion })}+\mathrm{AA}-$ $\mathrm{D}_{(\text {Crashes } / \mathrm{km} / \mathrm{yr})} \times \mathrm{AA}-\mathrm{D}_{\text {(Length Proportion) }}=2.017 \times 34.75 \%+5.073 \times 65.25 \%=4.011 .{ }^{4} \mathrm{AA}-\mathrm{Ch}_{(\text {Crashes } / \text { million veh-km) }}$ $\times \mathrm{AA}^{-} \mathrm{Ch}_{(\text {Length Proportion) }}+\mathrm{AA}-\mathrm{D}_{(\text {Crashes }} /$ million veh-km) $\times \mathrm{AA}-\mathrm{D}_{\text {(Length Proportion) }}=1.767 \times 34.75 \%+1.931 \times 65.25 \%$ $=1.874$.

\subsection{Engineering Mitigations}

The current study applied engineering mitigations or provided an alternative design for the identified hazardous road segments to improve safety, and, finally, the relative safety effects of the design alternatives were quantified. Hazardous road segments were inspected 
on the site as well as on Google Street View/Google Earth, and their design features were also checked against ERA standards by running the PRM of IHSDM and the findings of related studies before re-designing them. The design vehicle selected to run the PRM of IHSDM was WB-19/WB-62, which best fits the ERA design vehicle dimensions. Based on the examination of safety concerns, the hazardous road segments were redesigned to improve safety using the AutoCAD Civil 3D-2019 software. Since vertical alignment design necessitates detailed surface modeling via surveying or data collection and contour generation, the current study was dedicated to redesigning horizontal alignments in conjunction with cross-sections. For each identified hazardous road segment, the following design alternatives were provided.

\subsubsection{First-Ranked Hazardous Segment}

This segment is on the road from Addis Ababa to Dillela, at a station from $4+853.48$ to $4+862.57$. There is a circular curve with spiral curves on both sides having a radius of $100 \mathrm{~m}$ at this segment, and two curves with radiuses of $80 \mathrm{~m}$ and $120 \mathrm{~m}$ precede it, with a $30 \mathrm{~m}$ tangent length between them. At this segment, the following deficiencies are observed, as also confirmed by PRM evaluation: the curve radius is less than the ERA-2013 policy minimum, as the existing curve radius is $100 \mathrm{~m}$, whereas the policy minimum is $229 \mathrm{~m}$; the minimum controlling criteria for lane width is $7.3 \mathrm{~m}$, while the existing is $7.0 \mathrm{~m}$, and for shoulder width, it is $3.0 \mathrm{~m}$, while the existing is $1.5 \mathrm{~m}$; and the provided superelevation is inadequate. There is no stopping sight distance (SSD) issue. The design modifications made at this segment are as follows:

- The preceding two curves with a small tangent in between were changed to one circular curve and designed with adequate spiral curve length, which also helped to increase the radius of the next curve (the first hazardous segment) by providing an appropriate deflection angle within the existing road.

- Increasing the radius from $100 \mathrm{~m}$ to $394 \mathrm{~m}$ and moving the PI to obtain the existing road.

- $\quad$ Lane width increased to $7.3 \mathrm{~m}$ from $7.0 \mathrm{~m}$.

- $\quad$ Shoulder width increased to $2.0 \mathrm{~m}$ from $1.5 \mathrm{~m}$.

Figure 3 shows a more thorough depiction.

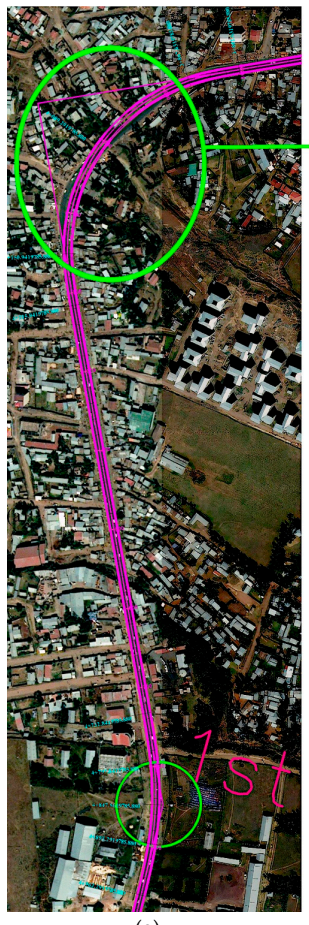

(a)
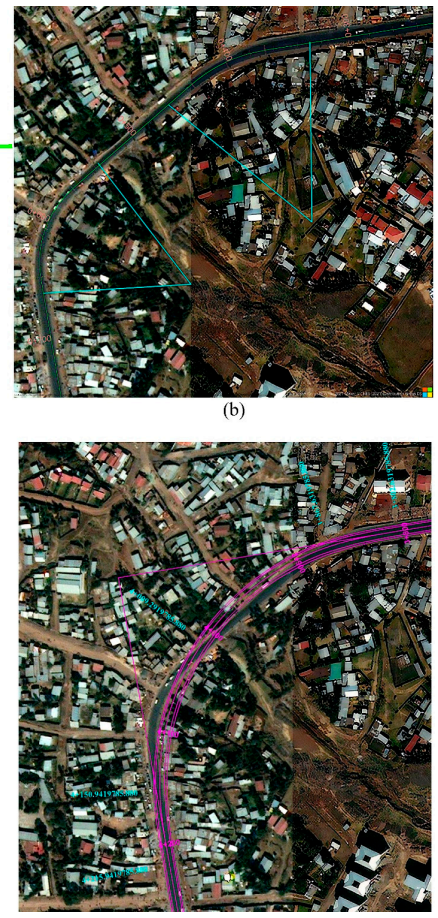

(c)

Figure 3. (a) The first-ranked hazardous road segment; (b) the compound curve of the existing road; and (c) the redesigned simple circular curve. 


\subsubsection{Second-Ranked Hazardous Segment}

This segment is found on the Addis Ababa to Chacha road. At this location, there are the 2nd and 14th ranked hazardous road segments with stations of $9+933.489$ to $9+971.900$ and $10+016.518$ to $10+204.330$, respectively. The curve radiuses that are found at the 2nd and 14th ranked hazardous segments are $190 \mathrm{~m}$ and $98 \mathrm{~m}$, respectively. PRM evaluation results and the observed deficiencies at these segments are as follows: for station $10+016.518$ to $10+204.330$, superelevation required, no superelevation identified, and the policy superelevation is $6.9 \%$. For station $9+969.489$ to $9+971.489$ on the right side of the road, the provided SSD is $67 \mathrm{~m}$, while the policy SSD is $70 \mathrm{~m}$ ('Road value varies from recommended values; check obstructions beyond shoulder; source of SSD limitation is horizontal alignment' where SSD is sight distance). Additionally, the minimum controlling criteria for lane width is $7.3 \mathrm{~m}$, while the existing is $7.0 \mathrm{~m}$, and for shoulder width, it is $3.0 \mathrm{~m}$, while the existing varies from 2.0 to $2.5 \mathrm{~m}$. The design modifications made at this segment are as follows:

- As illustrated in Figure 4, providing the policy minimum within the existing road alignment is difficult due to the short tangent between curves and their small curve length. Thus, engineering mitigation or design changes made here include removing a curve at the second hazardous segment and increasing the 14th hazardous curve radius from $98 \mathrm{~m}$ to $200 \mathrm{~m}$. Since there is a bridge on the 14th hazardous segment, the centerline was carefully passed on the bridge by adjusting the PIs (points of intersection) and curve radius.

- Additionally, the preceding curve radius was increased from $150 \mathrm{~m}$ to $200 \mathrm{~m}$.

- Adequate superelevation and SSD were provided.

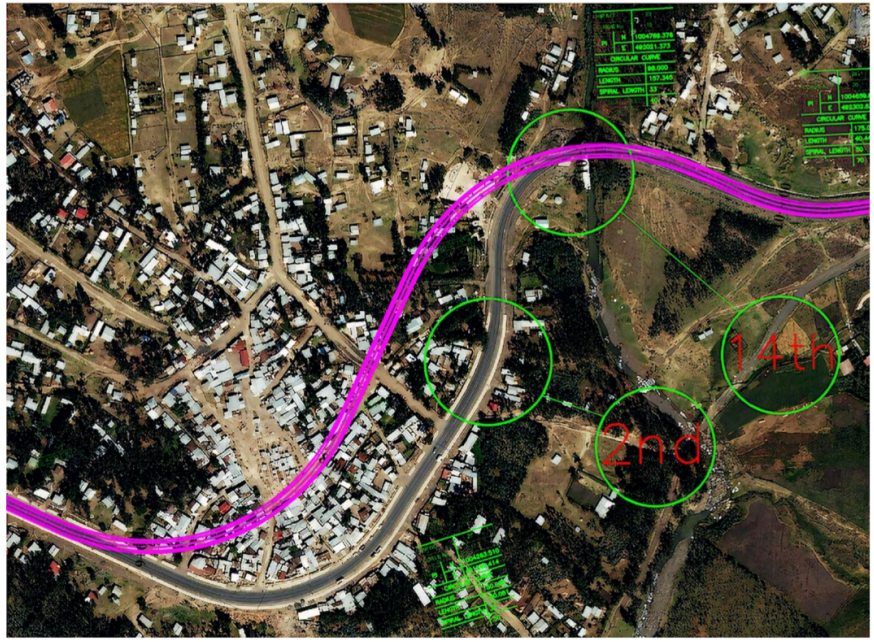

(a)

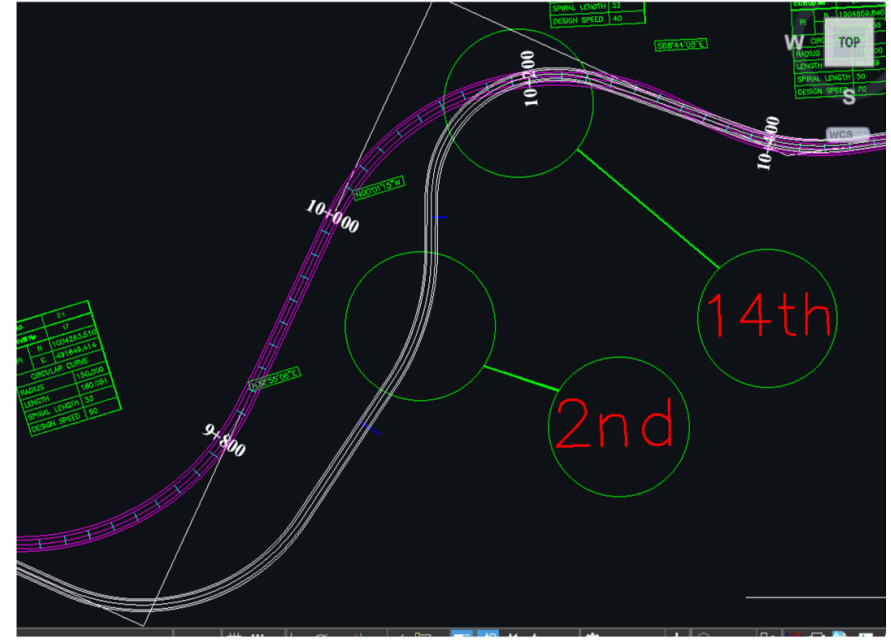

(b)

Figure 4. The second-ranked hazardous road segment (a) with satellite imagery; (b) without satellite imagery.

\subsubsection{Third-Ranked Hazardous Segment}

At this location, there are the 3rd and 15th ranked hazardous segments on Addis Ababa to Dillela road with the stations of $7+017.218$ to $7+104.199$ and $6+831.965$ to $6+922.933$, respectively. These curves are a reverse curve with a $94.28 \mathrm{~m}$ tangent length between them. PRM evaluation result and the observed deficiencies at this location are as follows: both radiuses are less than the ERA-2013 policy minimum, as the existing curve radiuses are $67.5 \mathrm{~m}$ and $163.2 \mathrm{~m}$ for the 3rd and 15th, respectively, whereas the policy minimum is $229 \mathrm{~m}$; the minimum controlling criteria for lane width is $7.3 \mathrm{~m}$, while the existing is $7.0 \mathrm{~m}$; and for shoulder width, it is $2.0 \mathrm{~m}$, while the existing is $1.5 \mathrm{~m}$. The design modifications made at this segment are as follows: 
- The radius of a curve found at the 3rd hazardous road segment was increased to $150 \mathrm{~m}$ (from $67.5 \mathrm{~m}$ ), and the preceding curve radius was increased to $200 \mathrm{~m}$ (from $163.2 \mathrm{~m}$ ). Their PIs were also adjusted to align on the existing road.

- Even if the radius of both curves were increased to the maximum by keeping in mind not to shift from the existing road, the minimum ERA policy for curve radius would not be not provided. However, the recommended superelevation based on the selected design speed and curve radius was provided for both curves.

- $\quad$ Lane width increased to $7.3 \mathrm{~m}$ from $7.0 \mathrm{~m}$.

- $\quad$ Shoulder width increased to $2.0 \mathrm{~m}$ from $1.5 \mathrm{~m}$.

Figure 5 shows a more thorough depiction.

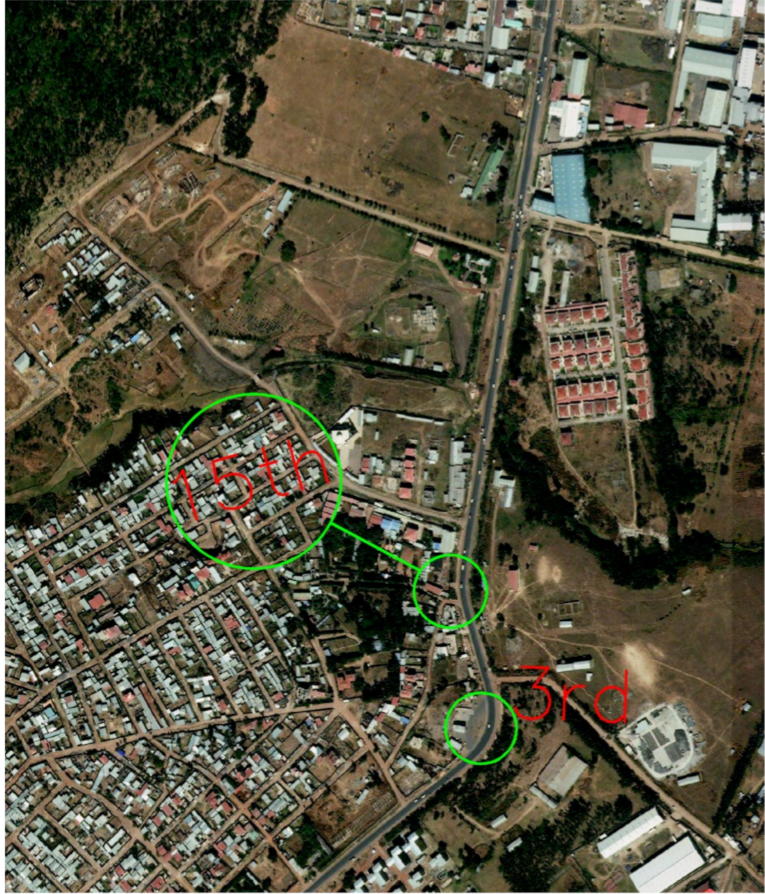

(a)

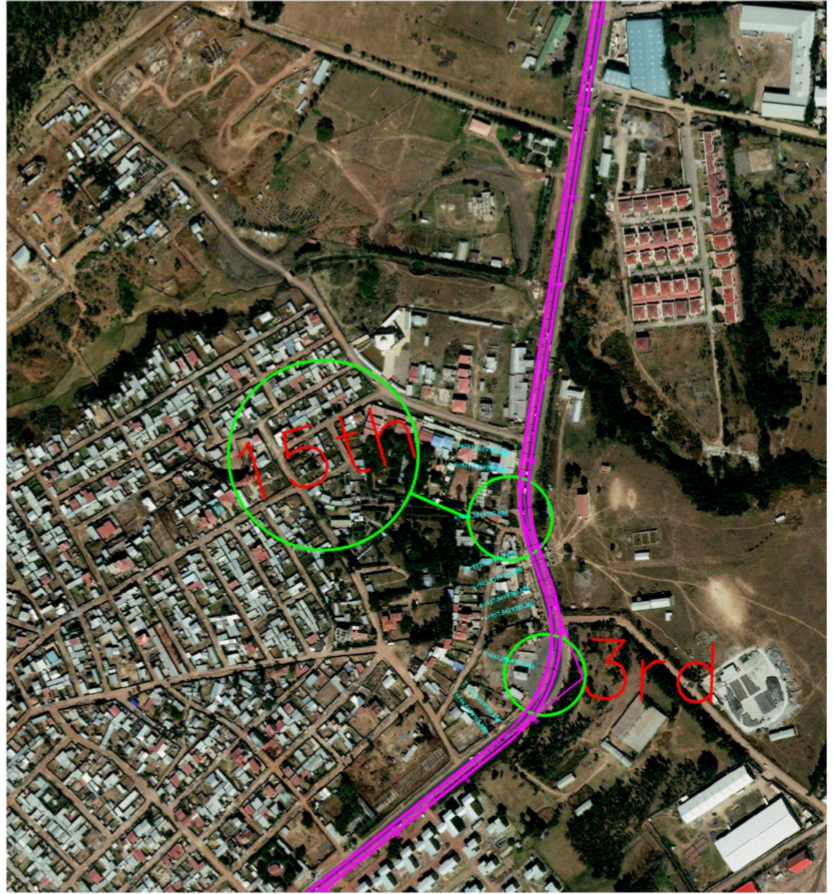

(b)

Figure 5. (a) The existing road at the third-ranked hazardous road segment; (b) re-designed.

\subsubsection{Fourth-Ranked Hazardous Segment}

The 4 th hazardous segment at station $11+972.179$ to $12+084.098$ and the 10 th hazardous segment at $12+124.150$ to $12+211.392$ are found at this location on Addis Ababa to Dillela road with curve radiuses of $64.5 \mathrm{~m}$ and $120.0 \mathrm{~m}$, respectively. At these segments, the following deficiencies were observed, as was also confirmed by the PRM evaluation: a sharp curve with a $64.5 \mathrm{~m}$ radius, the 4th ranked hazardous segment, is followed by another curve (the 10th hazardous segment) with a $40 \mathrm{~m}$ tangent length in between them; the minimum controlling criteria for lane width is $7.3 \mathrm{~m}$, while the existing is $7.0 \mathrm{~m}$; and for shoulder width, it is $3.0 \mathrm{~m}$, while the existing is $1.75 \mathrm{~m}$ for the first curve and $1.5 \mathrm{~m}$ for the preceding; and road value varies from controlling criteria; check obstructions beyond shoulder; source of SD limitation is horizontal alignment: SSD of the road at $11+852.00$ to $12+172.00$ in right direction is $64 \mathrm{~m}, 12+196.00$ to $12+396.00$ in the right is $80 \mathrm{~m}$, and $12+004.00$ to $12+314.00$ in the left is $58 \mathrm{~m}$ while policy SSD is $155 \mathrm{~m}$. The design modifications made at these segments are as follows:

- Modifying the alignment as shown in Figure 5 may be challenging owing to the short tangent between curves and their small curve length. The mitigation used in this study was to eliminate the next curve found at the 10th hazardous section in order to modify 
the sharp curve with a high crash rate. The radius of this sharp curve (the curve at the 4th hazardous segment) was increased to $120 \mathrm{~m}$ from $64.5 \mathrm{~m}$ as a result of this action.

- Furthermore, adequate superelevation and curve widening were provided.

- Indeed, the new alignment was somewhat shifted from that of the existing road so that a benefit/cost ratio analysis needs to be executed to assess the feasibility of this mitigation or alternative design. However, there is no agreed-upon or standardized crash cost in Ethiopia, which needs a detailed study. It is recommended in this paper that the feasibility of all the design alternatives or mitigations must be carried out in the future framework.

- $\quad$ Lane width increased to $7.3 \mathrm{~m}$ from $7.0 \mathrm{~m}$.

- $\quad$ Shoulder width increased to $2.0 \mathrm{~m}$ from $1.75 \mathrm{~m}$.

Figure 6 shows a more thorough depiction.

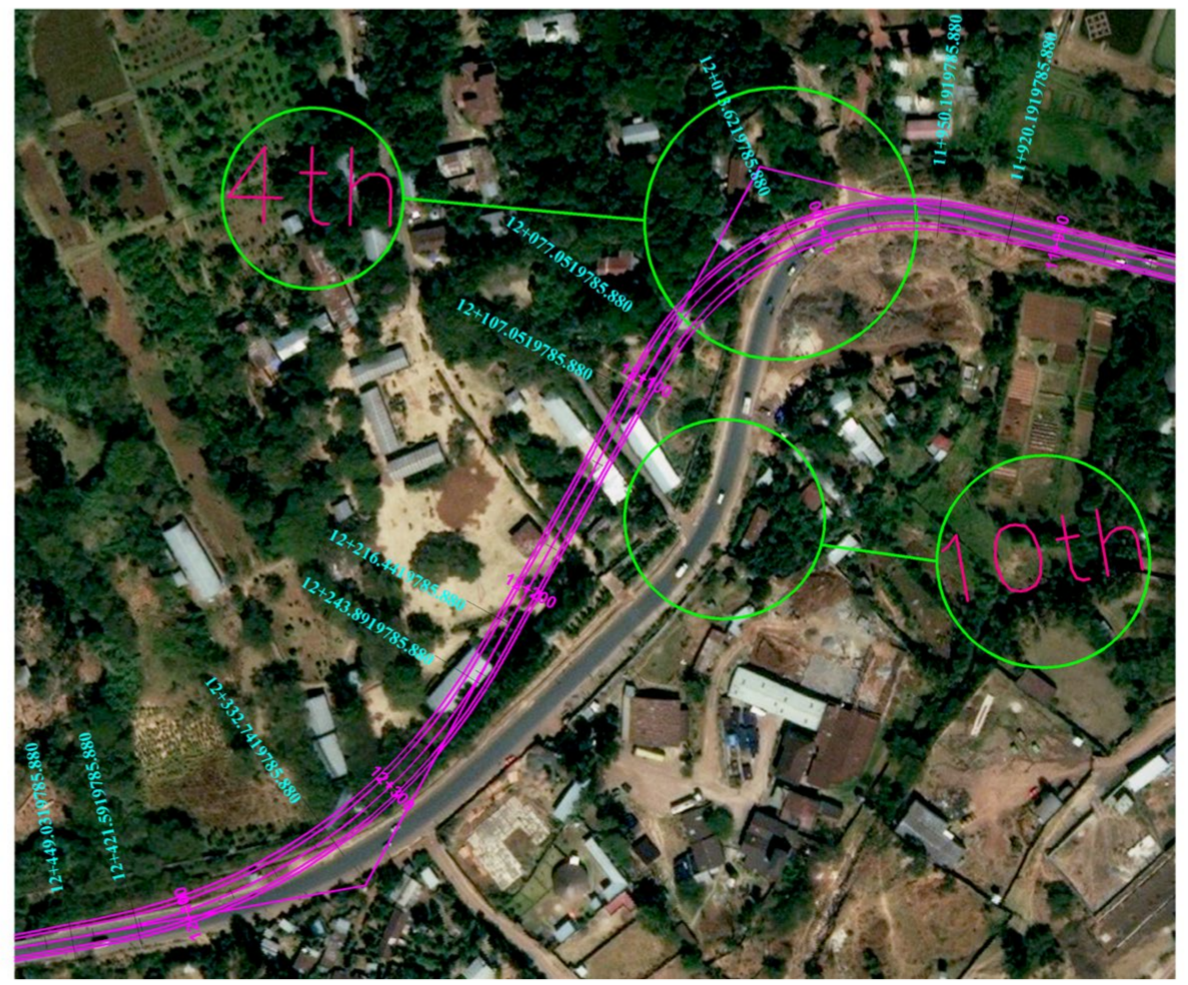

Figure 6. The fourth-ranked hazardous road segment.

\subsubsection{The Remaining Identified Hazardous Road Segments}

Table 5 shows the alternative designs or engineering mitigations applied to the remaining hazardous road segments following a thorough examination of their geometric design characteristics in conjunction with the Policy Review Module (PRM) evaluation results of IHSDM.

Table 5. Engineering mitigations made to the hazardous road segments.

\begin{tabular}{|c|c|c|c|c|}
\hline Rank & Road & Station & Measures & Remarks \\
\hline 5 th & AA-D & $\begin{array}{c}14+725.23 \text { to } 14 \\
+811.86\end{array}$ & $\begin{array}{l}\text { Radius increased to } 394 \mathrm{~m} \text { from } 120 \mathrm{~m} \text {; } \\
\text { Lane width increased to } 7.3 \mathrm{~m} \text { from } 7.0 \mathrm{~m} \text {; } \\
\text { Shoulder width increased to } 2.0 \mathrm{~m} \text { from } 1.5 \mathrm{~m} \text {. }\end{array}$ & A minimum radius is provided \\
\hline 6th & AA-D & $\begin{array}{c}9+650 \text { to } 9+ \\
664.21\end{array}$ & $\begin{array}{l}\text { Radius increased to } 250 \mathrm{~m} \text { from } 120 \mathrm{~m} \text {; } \\
\text { Lane width increased to } 7.3 \mathrm{~m} \text { from } 7.0 \mathrm{~m} \text {; } \\
\text { Shoulder width increased to } 2.0 \mathrm{~m} \text { from } 1.5 \mathrm{~m} \text {. }\end{array}$ & \\
\hline
\end{tabular}


Table 5. Cont.

\begin{tabular}{|c|c|c|c|c|}
\hline Rank & Road & Station & Measures & Remarks \\
\hline 7 th & $\mathrm{AA}-\mathrm{Ch}$ & $\begin{array}{c}29+008.49 \text { to } 29 \\
+043.27\end{array}$ & $\begin{array}{c}\text { Radius increased to } 370 \mathrm{~m} \text { from } 300 \mathrm{~m} ; \\
\text { Curve length increased; } \\
\text { Increasing curve widening. }\end{array}$ & $\begin{array}{l}\text { The existing curve radius is } \\
\text { sufficient but increasing curve } \\
\text { length makes the road comfortable. }\end{array}$ \\
\hline 8th & AA-D & $\begin{aligned} 11+ & 346.23 \text { to } 11 \\
+ & 445.48\end{aligned}$ & $\begin{array}{l}\text { Radius increased to } 100 \mathrm{~m} \text { from } 96.5 \mathrm{~m} \text {; } \\
\text { Lane width increased to } 7.3 \mathrm{~m} \text { from } 7.0 \mathrm{~m} \text {; } \\
\text { Shoulder width increased to } 2.0 \mathrm{~m} \text { from } 1.5 \mathrm{~m} \text {. }\end{array}$ & \\
\hline 9th & $\mathrm{AA}-\mathrm{Ch}$ & $\begin{array}{c}42+500.02 \text { to } 42 \\
+613.42\end{array}$ & $\begin{array}{l}\text { The tangent length between curves is increased to } \\
98 \mathrm{~m} \text { from } 22 \mathrm{~m} \text { by moving the PIs apart keeping } \\
\text { the bridge untouched. }\end{array}$ & $\begin{array}{l}\text { There are two circular curves with a } \\
\text { short tangent }(22 \mathrm{~m}) \text { between them. } \\
\text { Additionally, there is a bridge } \\
\text { between these curves, and it is } \\
\text { difficult to modify the alignment } \\
\text { due to the cost of bridges. }\end{array}$ \\
\hline 11th & AA-D & $\begin{array}{c}10+108.13 \text { to } 10 \\
+240.83\end{array}$ & $\begin{array}{l}\text { Radius increased to } 140 \mathrm{~m} \text { from } 103 \mathrm{~m} \text {; } \\
\text { Lane width increased to } 7.3 \mathrm{~m} \text { from } 7.0 \mathrm{~m} \text {; } \\
\text { Shoulder width increased to } 2.0 \mathrm{~m} \text { from } 1.5 \mathrm{~m} \text {. }\end{array}$ & \\
\hline 12 th & $\mathrm{AA}-\mathrm{Ch}$ & $\begin{array}{c}39+549.88 \text { to } 39 \\
+608.49\end{array}$ & $\begin{array}{l}\text { The tangent length between curves is increased to } \\
84 \mathrm{~m} \text { from } 41.5 \mathrm{~m} \text { by moving the PI's apart keeping } \\
\text { the bridge untouched. }\end{array}$ & $\begin{array}{l}\text { There are two circular curves with a } \\
\text { short tangent ( } 41.5 \mathrm{~m} \text { ) between them. } \\
\text { Additionally, there is a bridge } \\
\text { between these curves, and it is } \\
\text { difficult to modify the alignment } \\
\text { due to the cost of bridges. }\end{array}$ \\
\hline 13th & AA-D & $\begin{array}{c}15+643.7 \\
\text { to } 15+738.55\end{array}$ & $\begin{array}{l}\text { Radius increased to } 250 \mathrm{~m} \text { from } 134 \mathrm{~m} \text {; } \\
\text { Increasing curve widening; } \\
\text { Lane width increased to } 7.3 \mathrm{~m} \text { from } 7.0 \mathrm{~m} \text {; } \\
\text { Shoulder width increased to } 2.0 \mathrm{~m} \text { from } 1.5 \mathrm{~m} \text {. }\end{array}$ & \\
\hline
\end{tabular}

\subsection{Relative Safety Performance Evaluation of Design Alternatives}

All of the prescribed modifications for the hazardous road segments were completed using AutoCAD-Civil 3D software, and the ERA standard was imported into the software to be incorporated into the design of superelevation, curve widening, and adequate SSD provision. All geometric design changes made were imported into IHSDM software for further CPM analysis. For the sake of assessing relative safety performance, the CPM evaluation used a similar analysis period, crash distribution dataset, superelevation policy, and AADT. The predicted travel crash rate of the modified highways was summarized after running the CPM of IHSDM and is presented in Table 5.

Table 6 shows that there was a significant reduction in crash rate, particularly on the first top five hazardous segments, where astonishing improvements were noticed. For example, reducing the predicted travel crash rate (crashes/million veh- $\mathrm{km}$ ) from 4.84 to $0.55,2.79$ to $0.5,2.5$ to $0.78,2.29$ to 0.92 , and 2.1 to 0.54 , in ascending order of the first top-five inconsistencies modified, resulted in a safety benefit. Figure 6 depicts a graph of $\mathrm{CPM}$ results for the existing and redesigned hazardous segments of the 1st, 3rd, and 15th ranked to demonstrate the relative safety impacts of geometric changes. As exhibited in Figures 7 and 8 , the predicted crash rate at the first hazardous segment for the existing road was 12.72 crashes $/ \mathrm{km} /$ year; however, after improving the curve, shoulder, and lane width, the estimated crash rate was remarkably reduced to 1.43 crashes $/ \mathrm{km} /$ year. Similarly, by modifying the horizontal curves at the 3rd and 15th hazardous segments, the predicted crash rates were reduced from 6.57 to 2.04 and 3.67 to 2.38 crashes/ km/year, respectively. 
Table 6. CPM result of the alternative design.

\begin{tabular}{|c|c|c|c|c|c|}
\hline Highway & Title & $\begin{array}{l}\text { Start Location } \\
\text { (Station, m) }\end{array}$ & $\begin{array}{l}\text { End Location } \\
\text { (Station, } \mathrm{m})\end{array}$ & $\begin{array}{l}\text { Predicted Travel Crash Rate } \\
\text { (Crashes/Million veh-km) }\end{array}$ & Length (m) \\
\hline \multirow{3}{*}{$1(\mathrm{AA}-\mathrm{D})$} & Spiral Curve & $4+732.84$ & $4+797.84$ & 0.55 & \\
\hline & Simple Curve & $4+797.84$ & $4+897.29$ & 0.55 & 229.45 \\
\hline & Spiral Curve & $4+897.29$ & $4+962.29$ & 0.55 & \\
\hline \multirow[t]{2}{*}{$2(\mathrm{AA}-\mathrm{Ch})$} & Tangent & $9+831.72$ & $9+989.26$ & 0.5 & 157.54 \\
\hline & Spiral Curve & $6+937.56$ & $6+957.56$ & 0.78 & \\
\hline \multirow[t]{3}{*}{3 (AA-D) } & Simple Curve & $6+957.56$ & $7+126.60$ & 0.78 & 209.04 \\
\hline & Spiral Curve & $7+126.60$ & $7+146.60$ & 0.78 & \\
\hline & Spiral Curve & $11+920.19$ & $11+950.19$ & 0.92 & 186.86 \\
\hline \multirow[t]{3}{*}{$4(\mathrm{AA}-\mathrm{D})$} & Simple Curve & $11+950.19$ & $12+077.05$ & 0.92 & \\
\hline & Spiral Curve & $12+077.05$ & $12+107.05$ & 0.92 & \\
\hline & Spiral Curve & $14+596.86$ & $14+610.21$ & 0.54 & \\
\hline \multirow[t]{2}{*}{5 (AA-D) } & Simple Curve & $14+610.21$ & $14+839.93$ & 0.54 & 256.42 \\
\hline & Spiral Curve & $14+839.93$ & $14+853.28$ & 0.54 & \\
\hline \multirow{2}{*}{$6(\mathrm{AA}-\mathrm{D})$} & Spiral Curve & $9+650.00$ & $9+705.70$ & 1.1 & \\
\hline & Simple Curve & $9+650.00$ & $9+650.38$ & 2.01 & 55.70 \\
\hline \multirow[t]{2}{*}{7 (AA-Ch) } & Simple Curve & $29+416.37$ & $29+547.49$ & 0.74 & 131.12 \\
\hline & Spiral Curve & $11+287.18$ & $11+352.18$ & 1.13 & \\
\hline \multirow[t]{2}{*}{$8(\mathrm{AA}-\mathrm{D})$} & Simple Curve & $11+352.18$ & $11+378.53$ & 1.13 & 156.35 \\
\hline & Spiral Curve & $11+378.53$ & $11+443.53$ & 1.13 & \\
\hline \multirow{2}{*}{9 (AA-Ch) } & Simple Curve & $43+003.35$ & $43+120.09$ & 1.32 & 116.75 \\
\hline & Tangent & $12+107.05$ & $12+216.44$ & 0.45 & \\
\hline \multirow[t]{3}{*}{$10(\mathrm{AA}-\mathrm{D})$} & None & None & None & None & 109.39 \\
\hline & None & None & None & None & \\
\hline & Spiral Curve & $10+037.63$ & $10+102.63$ & 0.77 & \\
\hline \multirow[t]{2}{*}{11 (AA-D) } & Simple Curve & $10+102.63$ & $10+202.24$ & 0.84 & 229.61 \\
\hline & Spiral Curve & $10+202.24$ & $10+267.24$ & 0.85 & \\
\hline \multirow[t]{2}{*}{12 (AA-Ch) } & Simple Curve & $40+011.39$ & $40+085.37$ & 1.14 & 73.98 \\
\hline & Spiral Curve & $15+561.25$ & $15+576.16$ & 0.69 & \\
\hline \multirow{2}{*}{13 (AA-D) } & Simple Curve & $15+576.16$ & $15+711.45$ & 0.69 & 165.11 \\
\hline & Spiral Curve & $15+711.448$ & $15+726.361$ & 0.69 & \\
\hline \multirow[t]{2}{*}{14 (AA-Ch) } & Simple Curve & $9+989.261$ & $10+303.527$ & 0.75 & 314.27 \\
\hline & Spiral Curve & $6+793.198$ & $6+811.328$ & 0.95 & \\
\hline \multirow[t]{2}{*}{15 (AA-D) } & Simple Curve & $6+811.328$ & $6+897.435$ & 0.91 & 122.37 \\
\hline & Spiral Curve & $6+897.435$ & $6+915.565$ & 0.86 & \\
\hline
\end{tabular}

A comparison with the existing segments was conducted by totaling the predicted crash frequencies, crash rates, and travel crash rates in million vehicles for all fifteen modified segments, and the results are shown in Table 7. The geometric design changes made on these segments resulted in a reduction of $17.18 \%$ in total crash frequency (crashes/year), $58.94 \%$ in crash rate (crashes $/ \mathrm{km} /$ year), and $58.86 \%$ in travel crash rate (crashes $/$ million veh- $\mathrm{km}$ ). Because the crash rate was used as the primary safety threshold in the study, a solid crash percentage reduction was obtained. Modifying $0.89 \%$ of the total length of the roadways evaluated, such as the hazardous road segments, resulted in a $58.86 \%$ improvement in the travel crash rates. Even with a more than $100 \%$ increase in overall segment length, the total predicted crash frequency was reduced by $17.18 \%$. The overall length of the hazardous road segments modified increased due to increased curve radiuses and curve lengths. 


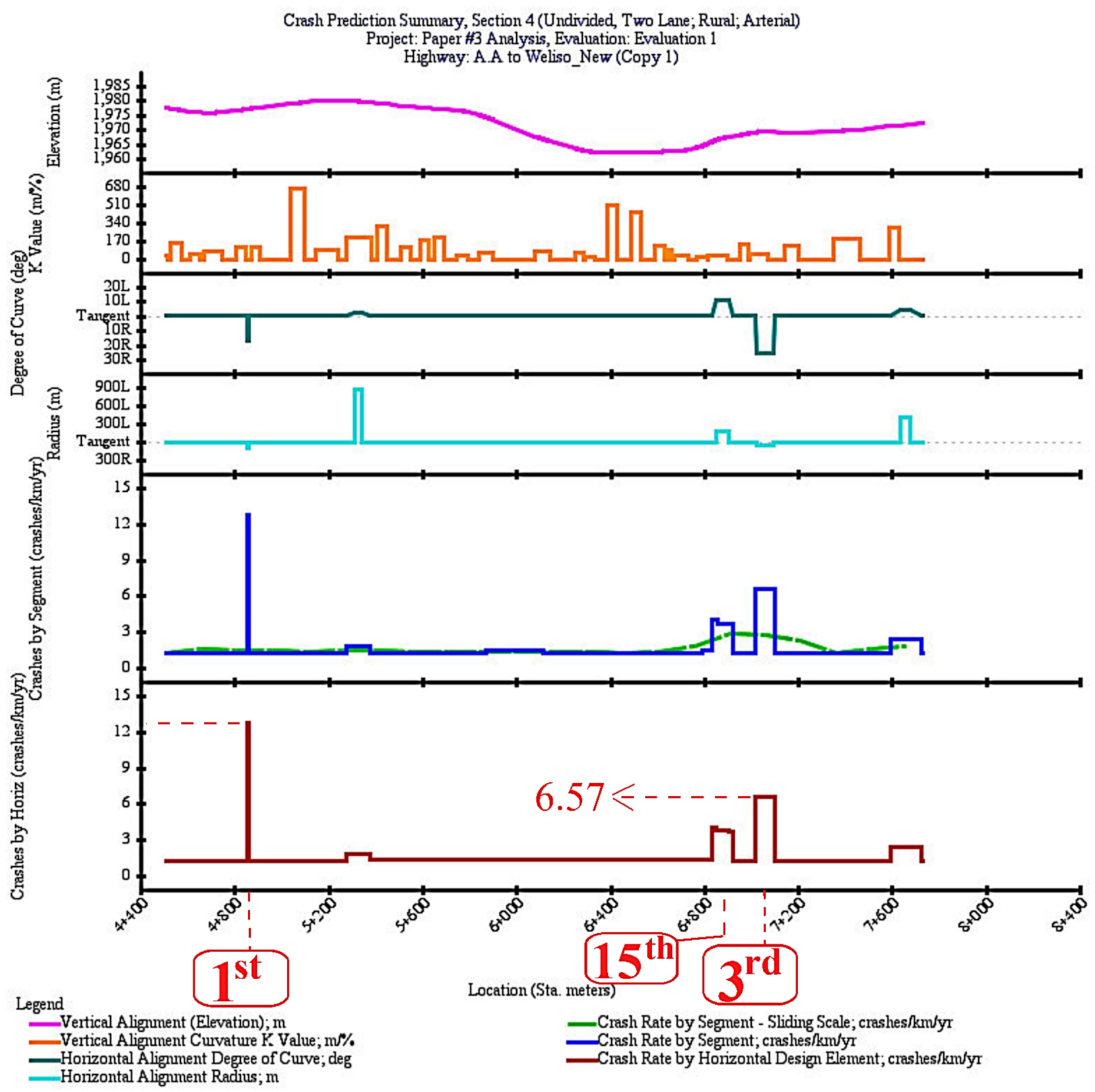

Figure 7. The existing CPM graph. 


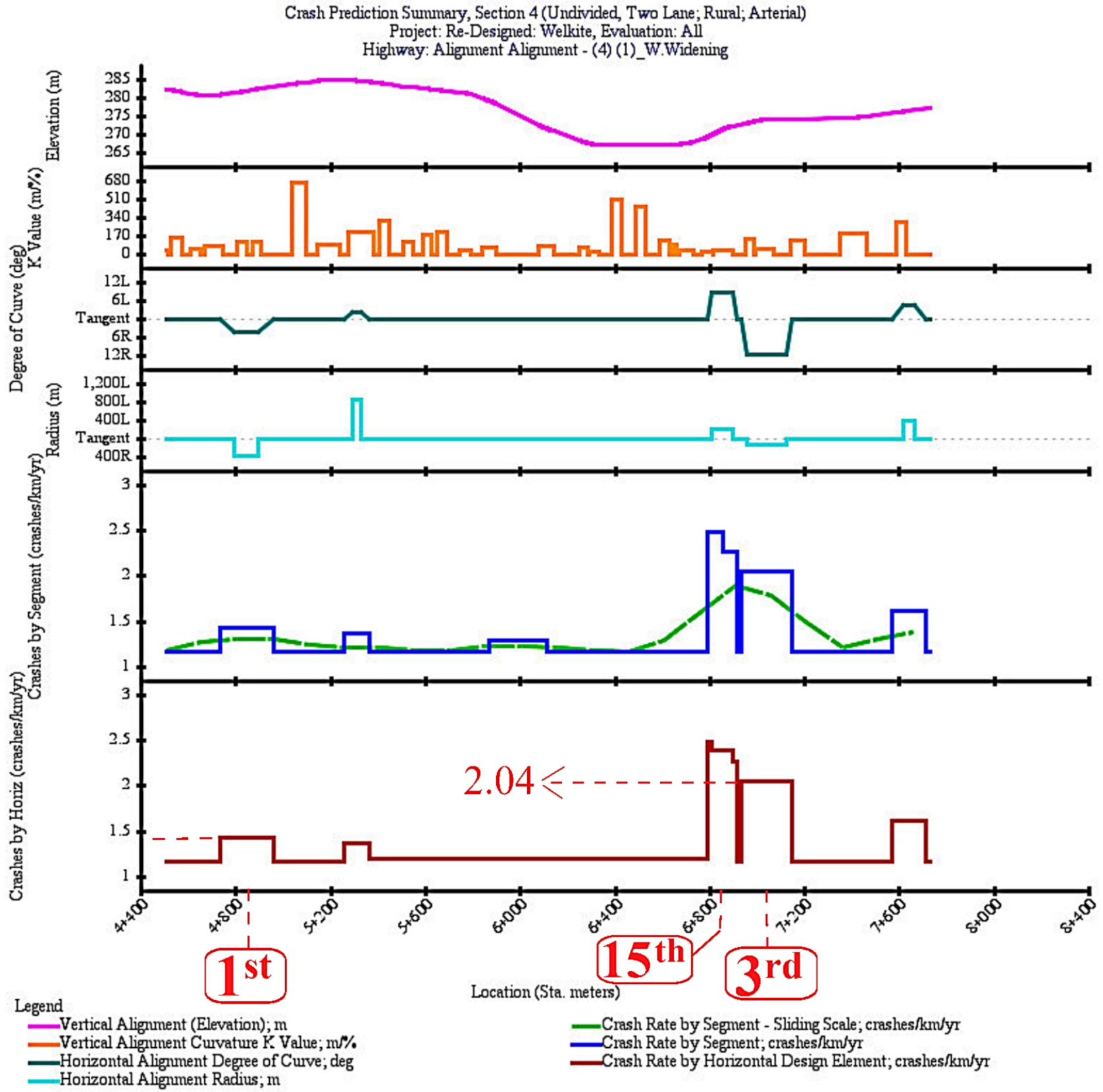

Figure 8. The re-designed CPM graph.

Table 7. The relative safety performance.

\begin{tabular}{cccccc}
\hline Title & Length $\mathbf{( k m )}$ & $\begin{array}{c}\text { Total Predicted } \\
\text { Crashes for } \\
\text { Evaluation Period }\end{array}$ & $\begin{array}{c}\text { Predicted Total } \\
\text { Crash Frequency } \\
\text { (Crashes/year) }\end{array}$ & $\begin{array}{c}\text { Predicted Crash } \\
\text { Rate }\end{array}$ & Length (km) \\
\hline Existing TOTAL & 1.246 & 99.980 & 5.00 & 4.011 & 1.874 \\
Re-Designed TOTAL & 2.514 & 82.808 & 4.141 & 1.647 & 0.771 \\
(Existing)-(Re-Designed) & -1.268 & 17.172 & 0.859 & 2.364 & 1.103 \\
Percentage reduction & $-101.72 \%$ & $17.18 \%$ & $17.18 \%$ & $58.94 \%$ & $58.86 \%$ \\
\hline
\end{tabular}




\section{Conclusions and Recommendations}

Safety evaluations based on road safety performance estimates (i.e., CPM evaluation) are an effective technique for identifying inconsistencies in a roadway network as well as quantifying the relative safety performance of design alternatives. In Ethiopia, however, road design standards based on the selection of design speed are regarded as the only surrogate measure of safety. This study aimed to fill the gap in using the predictive approach of road safety performance evaluation in Ethiopia by applying the most up-todate analytical methods of the HSM predictive approach in IHSDM software to evaluate the safety and operational effects of existing road geometric features and quantify the relative safety effects of design alternatives. From the selected roads for evaluation, the roads from Addis Ababa to Chacha and Addis Ababa to Dillela met the HSM model specification, and a study was conducted based on these roads.

The as-built geometric design and AADT data were collected from the Ethiopian Roads Authority (ERA), and all necessary information was imported and documented into IHSDM software for $\mathrm{CPM}$ evaluation. The hazardous road segments were identified and prioritized based on the predicted travel crash rate (crashes/million veh- $\mathrm{km}$ ) resulting from the CPM evaluation of each homogeneous roadway segment. Following the Policy Review Module (PRM) evaluation results, engineering mitigations were made for all identified hazardous road segments by redesigning them on AutoCAD Civil 3D software. The modified roadway segments were imported into IHSDM software for further CPM evaluation by substituting the existing hazardous segments. The relative safety effects of the design changes made in this study were compared to the existing roadway segments, and the benefits of the design changes were finally quantified.

The study discovered fifteen hazardous road segments on both the Addis Ababa to Chacha and Addis Ababa to Dillela roads based on the results of predicted travel crash rate (crashes/million veh-km) by horizontal design element. A total of $1.25 \mathrm{~km}$ in length of roadway segments was identified as hazardous, accounting for $0.89 \%$ of the total $140.66 \mathrm{~km}$ of rural roads evaluated. As a whole, the average predicted crash rate for rural roads evaluated is 0.998 (crashes $/ \mathrm{km} /$ year), whereas the predicted crash rate for hazardous road segments is 4.011 (crashes $/ \mathrm{km} /$ year), demonstrating that the identified hazardous segments are more than four times as hazardous and clearly have safety issues. Thus, applying engineering mitigations to these segments has the potential to economically improve overall road safety. The design modifications made on the hazardous road segments resulted in an impressive reductions in crash rate, particularly on the first top-five hazardous segments, where astounding improvements were witnessed. For instance, design changes made in this study to the first top-five geometrically hazardous segments yielded a reduction in predicted travel crash rate (crashes/million veh- $\mathrm{km}$ ) to 0.55 from 4.84, 0.5 from $2.79,0.78$ from 2.5, 0.92 from 2.29, and 0.54 from 2.1 in ascending order. The following are the aggregated safety benefits obtained by applying engineering mitigations to the fifteen identified hazardous segments: Total crash frequency (crashes/year) reduced by $17.18 \%$, crash rate (crashes $/ \mathrm{km} /$ year) reduced by $58.94 \%$, and travel crash rate (crashes $/$ million veh- $\mathrm{km}$ ) reduced by $58.86 \%$. Crash frequency indeed increases with road length, which is also true in HSM's SPF model; however, with a more than $100 \%$ increase observed in the total length of hazardous road segments modified, the total predicted crash frequency was reduced by $17.18 \%$.

The current study revealed the effectiveness of safety performance-based road evaluation or design in providing safe, efficient, and economically viable roadway infrastructure. IHSDM results aid decision-making in the roadway design process by providing a quantitative evaluation of the safety impact of different design features. Furthermore, when properly implemented, IHSDM is a tool capable of saving time for Road Safety Audit (RSA) teams and detecting road segments with safety issues. This study encourages transportation agencies to practice IHSDM as a decision-support tool during the RSA process to assess and estimate the safety and operation effects of different geometric design parameters for new and existing roads. Jurisdiction-specific SPFs for Ethiopian roads must be developed, 
or HSM's SPFs must be calibrated, in order to achieve an accurate roadway safety performance prediction and also to evaluate the transferability of the SPFs to Ethiopia. To do so, the observed crash locations must be precisely recorded so that they can be assigned to their proper roadway segments or intersections. In Ethiopia, there is no computerized crash recording database; instead, crash recording is manual and paper-based, with no georeferenced crash locations [31,38]. As a result, it is recommended that the Ethiopian Ministry of Transport work on developing crash database recording that is capable of documenting all crash characteristics, including crash locations using high-precision GPS technology, for the prospective road safety study. Furthermore, to assess the viability of the mitigations or alternative designs made in this study, a benefit/cost ratio analysis must be performed. However, there is no agreed-upon or standardized crash costing platform in Ethiopia, which necessitates a thorough investigation. The economic analysis of all design changes or mitigations made is then recommended to be investigated in the future framework.

Author Contributions: Conceptualization, A.M.T. and A.G.; methodology, A.M.T. and A.G.; software, A.M.T.; data curation, A.M.T.; writing-original draft preparation, A.M.T.; writing-review and editing, A.G., T.A.D. and F.S.; supervision, A.G., T.A.D. and F.S. All authors have read and agreed to the published version of the manuscript.

Funding: This research was part of the DAAD-EECBP Homegrown Ph.D. Program-2018. The APC was funded by the Open Access Publication Fund of the University of Rostock and the German Research Foundation (DFG).

Institutional Review Board Statement: Not applicable.

Informed Consent Statement: Not applicable.

Data Availability Statement: The data used in this study are available from the corresponding author upon reasonable request.

Acknowledgments: We would like to thank the Ethiopian Roads Authority (ERA) for providing the as-built geometric design of the studied roads as well as the average annual daily traffic (AADT) data. It is our pleasure to thank the German Academic Exchange Service (DAAD) for issuing a Ph.D. scholarship to the first author.

Conflicts of Interest: The authors declare no conflict of interest.

\section{References}

1. Qin, X.; Chen, Z.; Cutler, C.; Vachal, K. Evaluating Local and Tribal Rural Road Design with the Interactive Highway Safety Design Model (IHSDM). In DP-264; Upper Great Plains Transportation Institute, North Dakota State University: Fargo, ND, USA, 2013; p. 54.

2. Persaud, B.N. Statistical Methods in Highway Safety Analysis: A Synthesis of Highway Practice; Transportation Research Board of the National Academies: Washington, DC, USA, 2001; ISBN 0-309-06905-X.

3. Hauer, E.; Kononov, J.; Allery, B.; Griffith, M.S. Screening the Road Network for Sites with Promise. Transp. Res. Rec. 2002, 1784, 27-32. [CrossRef]

4. AASHTO. Highway Safety Manual, 1st ed.; American Association of State Highway and Transportation Officials: Washington, DC, USA, 2010.

5. Montella, A. A Comparative Analysis of Hotspot Identification Methods. Accid. Anal. Prev. 2010, 42, 571-581. [CrossRef] [PubMed]

6. Elvik, R. State-of-the-Art Approaches to Road Accident Black Spot Management and Safety Analysis of Road Networks; Institute of Transport Economics: Oslo, Norway, 2007.

7. Montella, A. Safety Reviews of Existing Roads: Quantitative Safety Assessment Methodology. Transp. Res. Rec. J. Transp. Res. Board 2005, 1922, 62-72. [CrossRef]

8. $\quad$ Reurings, M.; Janssen, T.; Eenink, R.; Elvik, R.; Cardoso, J.; Stefan, C. Accident Prediction Models and Road Safety Impact Assessment: Recommendations for Using These Tools; European Commission: Brussels, Belgium, 2006.

9. Thompson, J.; Jurewicz, C.; Thompson, B. Crash Risk Estimation and Assessment Tool. In Proceedings of the Australasian Road Safety Research, Policing and Education Conference; Australian Transport Council, National Convention Centre: Canberra, Australia, 2010.

10. Greibe, P. Accident Prediction Models for Urban Roads. Accid. Anal. Prev. 2003, 35, 273-285. [CrossRef] 
11. Peltola, H.; Rajamäki, R.; Luoma, J. A Tool for Safety Evaluations of Road Improvements. Accid. Anal. Prev. 2013, 60, 277-288. [CrossRef] [PubMed]

12. Cafiso, S.; Montella, A.; D'Agostino, C.; Mauriello, F.; Galante, F. Crash modification functions for pavement surface condition and geometric design indicators. Accid. Anal. Prev. 2021, 149, 105887. [CrossRef] [PubMed]

13. Ambros, J.; Jurewicz, C.; Turner, S.; Kieć, M. An International Review of Challenges and Opportunities in Development and Use of Crash Prediction Models. Eur. Transp. Res. Rev. 2018, 10, 35. [CrossRef]

14. Lord, D.; Mannering, F. The Statistical Analysis of Crash-Frequency Data: A Review and Assessment of Methodological Alternatives. Transp. Res. Part A Policy Pract. 2010, 44, 291-305. [CrossRef]

15. Yannis, G.; Dragomanovits, A.; Laiou, A.; Richter, T.; Ruhl, S.; La Torre, F.; Domenichini, L.; Graham, D.; Karathodorou, N.; Li, H. Use of Accident Prediction Models in Road Safety Management-An International Inquiry. Transp. Res. Procedia 2016, 14, 4257-4266. [CrossRef]

16. Jurewicz, C.; Steinmetz, L.; Turner, B. AP-R451-14; Austroads Ltd.: Sydney, Australia, 2014; p. 76.

17. Yannis, G.; Dragomanovits, A.; Laiou, A.; La Torre, F.; Domenichini, L.; Richter, T.; Ruhl, S.; Graham, D.; Karathodorou, N. Development of an online Repository of Accident Prediction Models and Crash Modification Factors. In Proceedings of the 1st European Road Infrastructure Congress; European Union Road Federation, Leeds, UK, 18-20 October 2016.

18. NZTA. Crash Estimation Compendium (New Zealand Crash Risk Factors Guideline), 1st ed.; The NZ Transport Agency: Wellington, New Zealand, 2016.

19. Paniati, J.F.; True, J. Interactive Highway Safe1y Design Model (IHSDM): Designing Highways with Safety in Mind. In Proceedings of the Roadside Safety Issues Revisited; Transportation Research Board: Washington, DC, USA, 1996; pp. 55-60.

20. Federal Highway Administration. Interactive Highway Safety Design Model (IHSDM): Overview. Available online: https:/ /highways.dot.gov/research/safety/interactive-highway-safety-design-model/interactive-highway-safety-designmodel-ihsdm-overview (accessed on 17 March 2020).

21. Office of Research and Technology, Federal Highway Administration. Interactive Highway Safety Design Model (IHSDM): Modules. Available online: https://highways.dot.gov/research/interactive-highway-safety-design-model/modules/modules (accessed on 3 January 2022).

22. Federal Highway Administration. Safer Roads Through Better Design: Using the Interactive Highway Safety Design Model. Available online: https:/ /highways.dot.gov/sites/fhwa.dot.gov/files/docs/research/project-sites/interactive-highway-safetydesign-model/506/fhwasa17011.pdf (accessed on 3 January 2022).

23. Donnell, E.T.; Gross, F.; Stodart, B.P.; Opiela, K.S. Appraisal of the Interactive Highway Safety Design Model's Crash Prediction and Design Consistency Modules: Case Studies from Pennsylvania. J. Transp. Eng. 2009, 135, 62-73. [CrossRef]

24. Conkin, W.; Stamatiadis, N. Evaluation of US 119 Pine Mountain Safety Improvements: Ihsdm Analysis of Post Construction; Kentucky Transportation Center: Lexington, KY, USA, 2004.

25. Chuo, K.; Saito, M. Applicability of FHWA Crash Prediction Module to Selecting Candidate Locations for Safety Audits of Two-Lane Rural Highways. Transp. Res. Rec. J. Transp. Res. Board 2009, 2137, 20-28. [CrossRef]

26. Maji, A.; Jha, M.K.; Kühn, W. Integrating Highway Alignment Design Capability to the Interactive Highway Safety Design Model (IHSDM): A Two-Lane Highway Case Study. In Proceedings of the Urban Transport XII: Urban Transport and the Environment in the 21st Century, Valencia, Spain, 19-21 September 2022; WIT Press: Southampton, UK, 2006; Volume 89, pp. 389-398.

27. ERA (Ethiopian Roads Authority). Geometric Design Manual; Federal Democratic Republic of Ethiopia: Addis Ababa, Ethiopia, 2013.

28. Fitzpatrick, K.; Wooldridge, M.D.; Tsimhoni, O.; Collins, J.; Green, P.; Bauer, K.; Parma, K.; Koppa, R.; Harwood, D.; Anderson, I.; et al. Alternative Design Consistency Rating Methods for Two-Lane Rural Highways (FHWA-RD-99-172); FHWA, U.S. Department of Transportation: Washington, DC, USA, 2000; p. 162.

29. Shin, H.; Lee, Y.-J.; Dadvar, S. MD-14-SP209B4J; Maryland State Highway Administration: Hanover, Germany, $2014 ;$ p. 130.

30. Tola, A.M.; Demissie, T.A.; Saathoff, F.; Gebissa, A. Crash Distribution Dataset: Development and Validation for the Undivided Rural Roads in Oromia, Ethiopia. Transp. Telecommun. 2022, 23, 11-24. [CrossRef]

31. UNECE (United Nations Economic Commission for Europe). Road Safety Performance Review—Ethiopia; United Nations: Geneva, Switzerland, 2021; ISBN 9789210055482.

32. Wemple, E.; Foster, N.; Bergh, C. Application of the Highway Safety Manual to Predict Crash Frequency. In Proceedings of the ATRF 2010: 33rd Australasian Transport Research Forum, Canberra, Australia, 29 September-1 October 2010; pp. 1-16.

33. World Population Prospects 2019. Available online: https://population.un.org/wpp/Download/Standard/Population/ (accessed on 3 January 2022).

34. Jonsson, T.; Lyon, C.; Ivan, J.N.; Washington, S.P.; Van Schalkwyk, I.; Lord, D. Differences in the Performance of Safety Performance Functions Estimated for Total Crash Count and for Crash Count by Crash Type. Transp. Res. Rec. 2009, 2102, 115-123. [CrossRef]

35. Persaud, B.N.; Retting, R.A.; Lyon, C.A. Crash Reduction Following Installation of Centerline Rumble Strips on Rural Two-Lane Roads. Accid. Anal. Prev. 2004, 36, 1073-1079. [CrossRef] [PubMed]

36. Brimley, B.; Saito, M.; Schultz, G. Calibration of Highway Safety Manual Safety Performance Function. Transp. Res. Rec. 2012, 2279, 82-89. [CrossRef] 
37. Aram, A. Effective Safety Factors on Horizontal Curves of Two-Lane Highways. J. Appl. Sci. 2010, 10, 2814-2822. [CrossRef]

38. Tola, A.M.; Demissie, T.A.; Saathoff, F.; Gebissa, A. Severity, Spatial Pattern and Statistical Analysis of Road Traffic Crash Hot Spots in Ethiopia. Appl. Sci. 2021, 11, 8828. [CrossRef] 